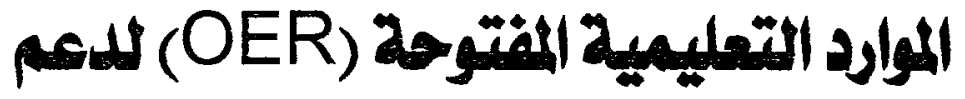 \\ التعلم المستمر لدى خريجي الجامعات المعات \\ السعودية الواقع والمامول
}

\author{
s) \\ الرايمان عبد الله حسين عسيري \\ معلمترياضياتادارة التعليم بمدينتينيعي
}




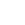




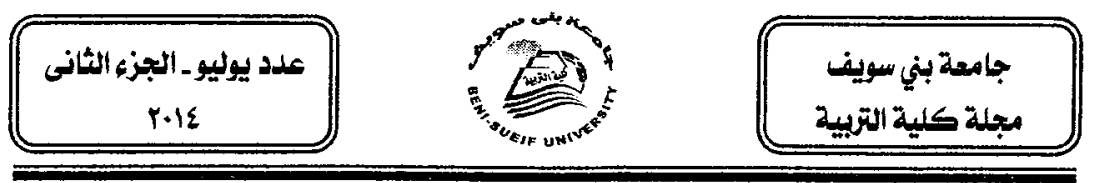

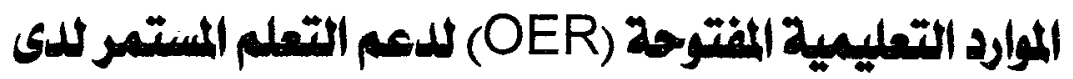 خريجي الجبامعات السعودية الواتح والمأمول

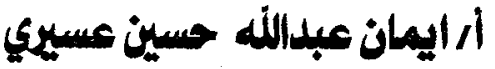 \\ معلمتربياضياتـ ادارة التعليم بمدينتينيع}

الملخص

هدفت هذه الدراسة إلى الكشف عن مدى معرفة خريجي الجامعات

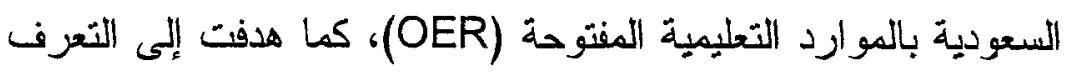
على فوائد استخدام الموارد من ثبل الخريجين، بالإضافة إلى إيراز

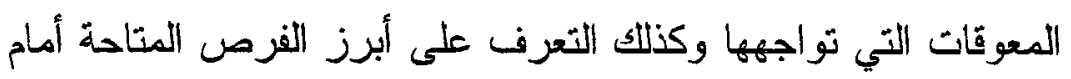

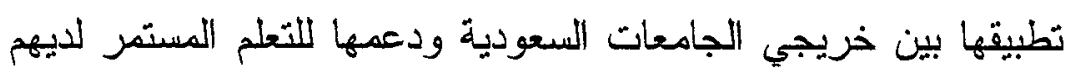
باعنبار هم اللبنة الأولى في بناء وتقدم المجتمع البعودي.

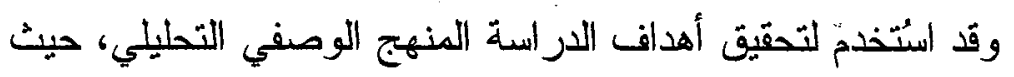
تكوّن مجتمع الدراسة من جميع خريجي جامعات المملكة العربية

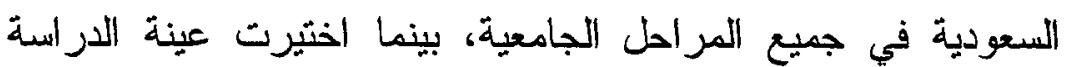
بصورة عشوائية وشملت (بو (1) خريج في مختلف التخصصات العلمية بالجامعات السعودية، وقد تم استخدام الاستبيان المغلق كأداة

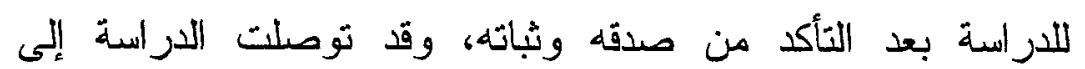
مجموعة من النتائج، تم في ضوئها صياغة مجموعة من التوصيات و الار اسات المستقبلية المقترحة.

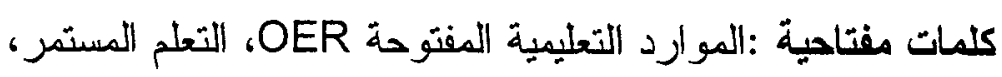
خريجي الجامعات السعودية: الواقع و المأمول. 


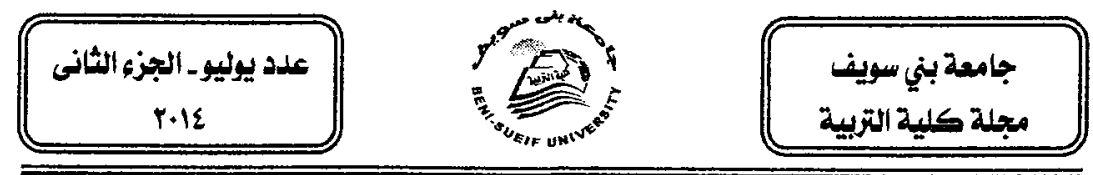

أولا :الإطار العام للاراسة

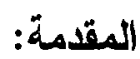

يحُظى التعليم العالي بأهمية كبيرة ومكانة مرموقة في سلم النظام

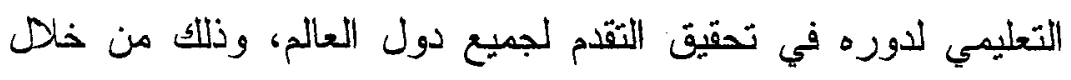

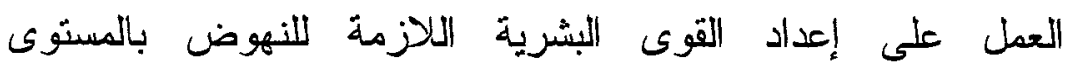

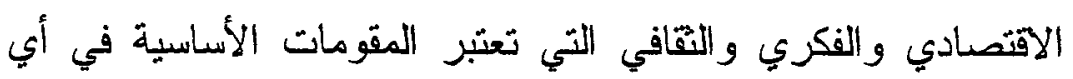
دولة نهذف إلى تحسين مسنواها التعليمي عالميأ و إقليميأ.

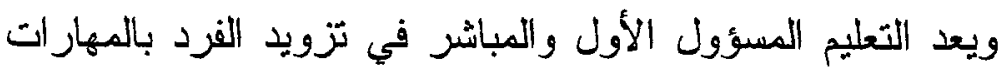
والقدرات والكفاءات المختلفة التي نعيذه على الوفاء بمنطلبات الحياة

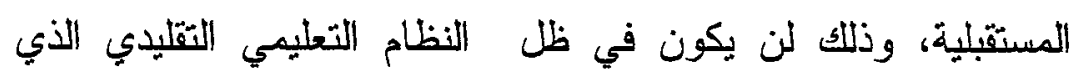
قو امه الموضوعية والواقعية وإنما عن طريق تبني سياسيات نعليمية

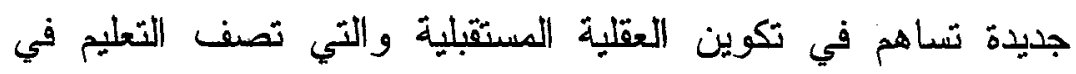

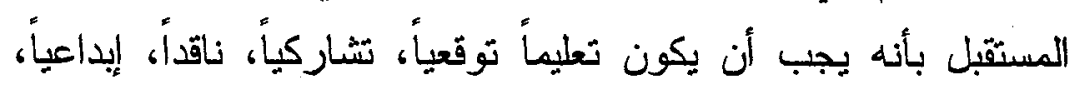

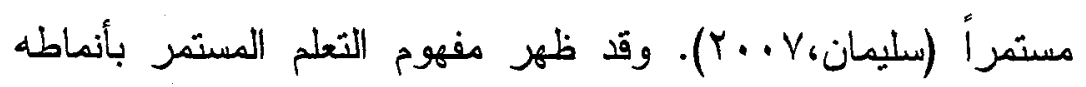

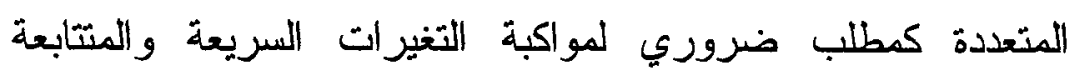
للمعارف والمفاهيم الذي يهذف إلى التجديد والتطوير لما فيه خدمة للمجتمع عامة وللفرد خاصة بتشجيعه على التعلم الذاتي سواء كان المبل

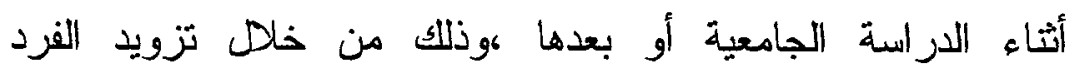

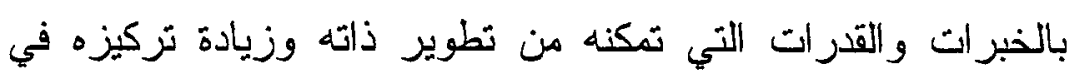

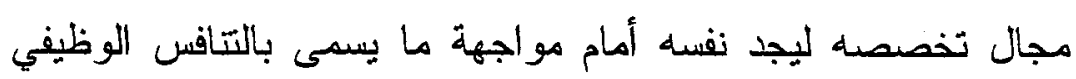

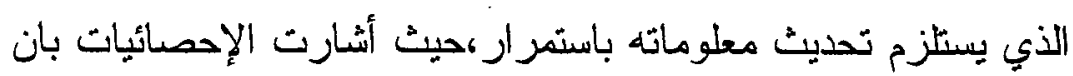

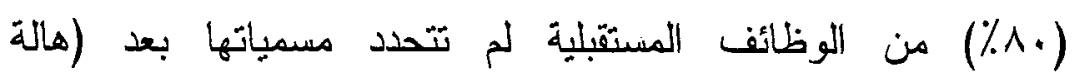
عيد، (T) 


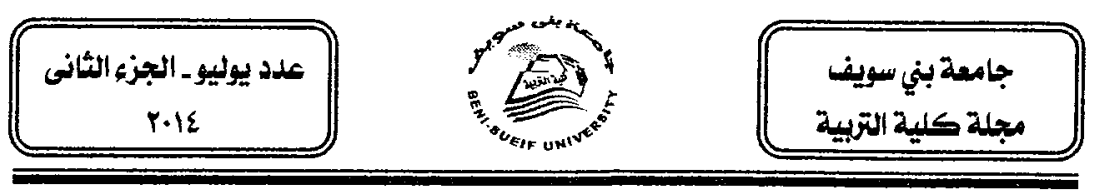

ويتميز العصر الحالي بالتقدم العلمي والتكنولوجي في شتى مجالات الحياة اليومية، حيث أصبح استخدام واستثمار الإمكانيات الحاسوبية اليوم واحداً هن صور تكنولوجيا التعليم الحديثة ، وتعنبر الموارد المداد

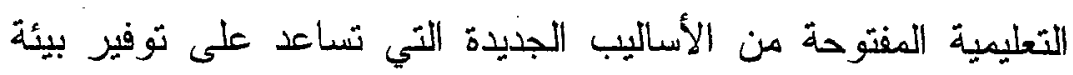
تعليمية تفاعلية ذات تصميم محكم تتيح للفرد المشاركة البناءة

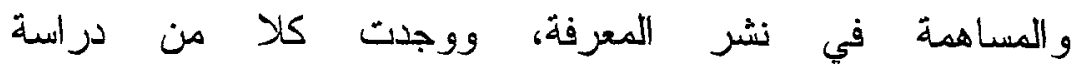
(Kozinska,....et.,2010) فوائد كثيرة أهمها :تحقيق ديمقراطية التعليم العالي، ونكافؤ الفرص ونس التعليمية لتشمل جميع الفئات العمرية ، كما أوضحت درئ دراسة (Sclater,2010) تتصدرها ارتفاع نسبة محو الأمية والبطالة المنتشرة في المناطق التي لهاي لا بتمكن أفرادها من مواصلة تعليمهم العالي وهذا بدوره يقلل من احتمالية توظيفهم أو حصولهم على وظيفة مناسبة تمكنهم من التقدم الاجتماعي وتشجعهم على مواجهة الواقع الاقتصادي الذي يعيشه العالم اليوم . الاجم

وفي ظل العولمة و التطورات المستمرة في المعلومات والخبرات

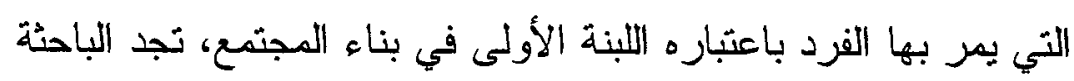

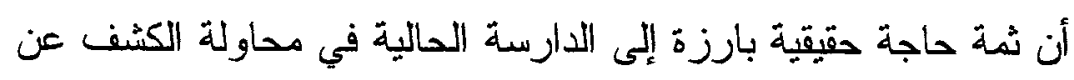

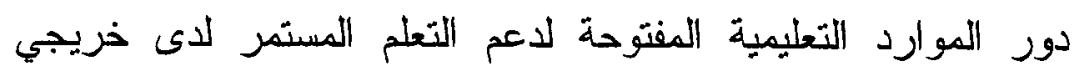

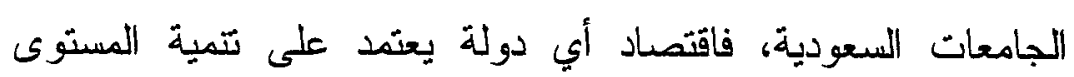

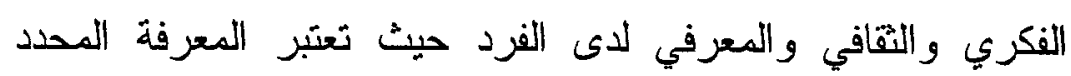
الرئبسي للتقدم البشري فأصبح لزامأ على الدول تذريب وتأهيل أفرادها بما بيتو افق مع احتياجات سوق العمل . 


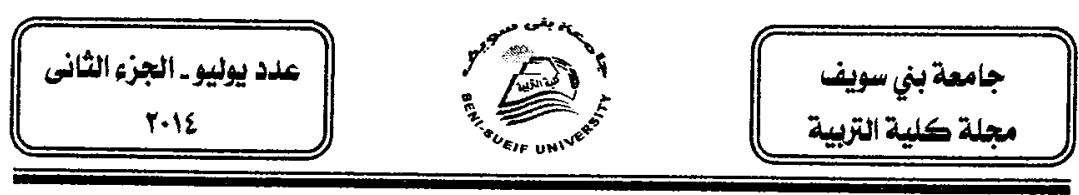

مشكلة وأسئلة الدراسة :

اهتمت مؤسسات التعليم العالي في المملكة العربية السعودية في التئية

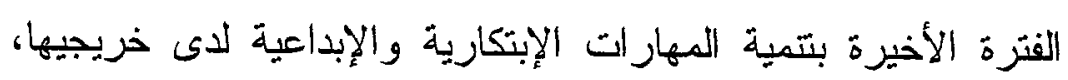

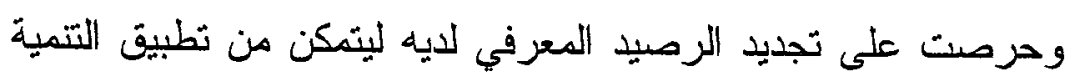

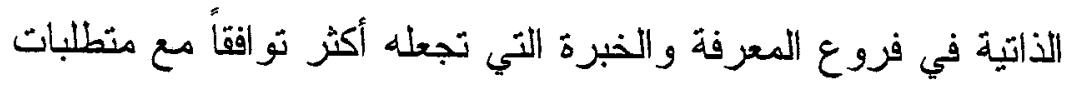

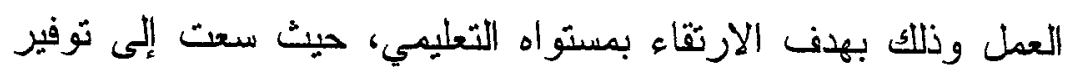

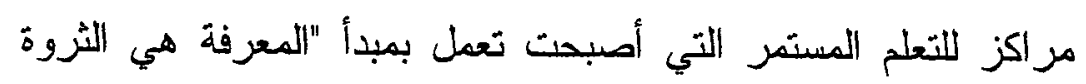

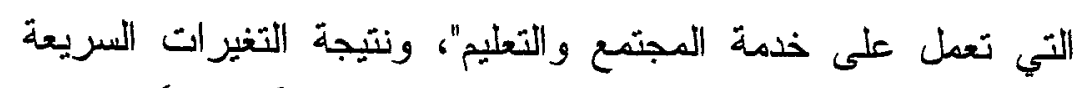

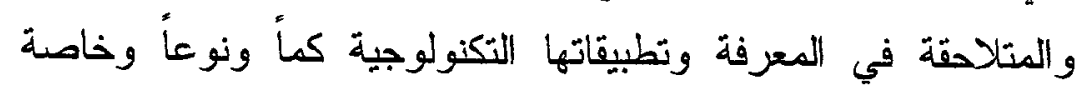

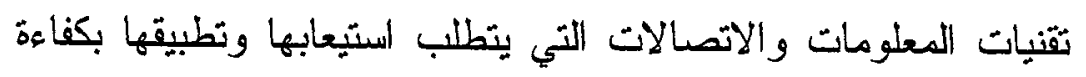
من قبل الخريجين، اتجهت معظم الدول المتقدمة إلى استخدام الموارد

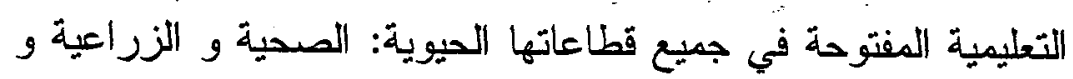

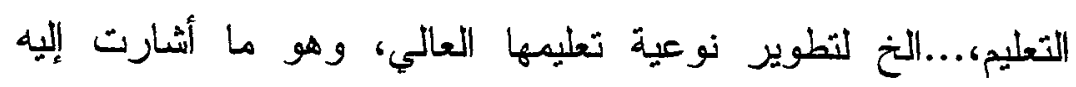

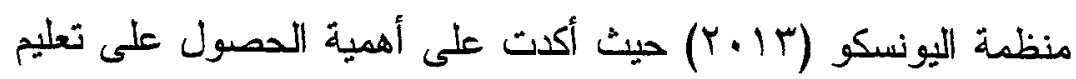
عالي الجودة يساهم في التتبة الاقتصادية والاجتماعية في البلدان

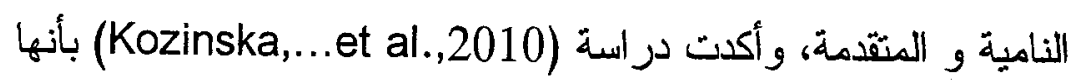
أصبحت جزأ مهمًا من مجتمع اليوم وعنصرًا هامًا في مستقبل

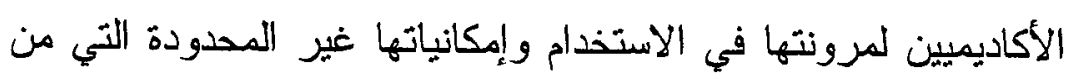

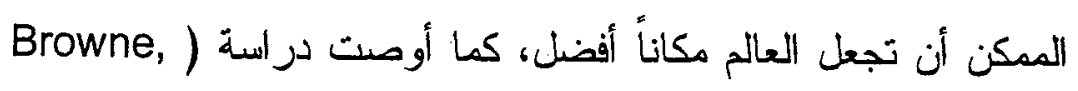
بوolding ,Howell \& Dyer,2010 بكيفية التوظيف الجيد للموارد التعليمية المفتوحة من قبل الخريجين لتطوير هم مهنيأ، ولعل من أهم التحديات التي نواجه مؤسسات التعليم

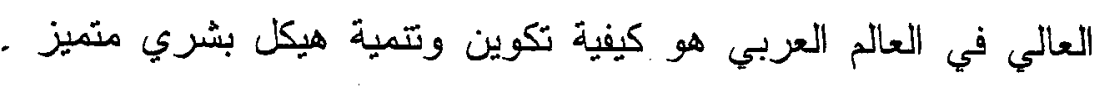




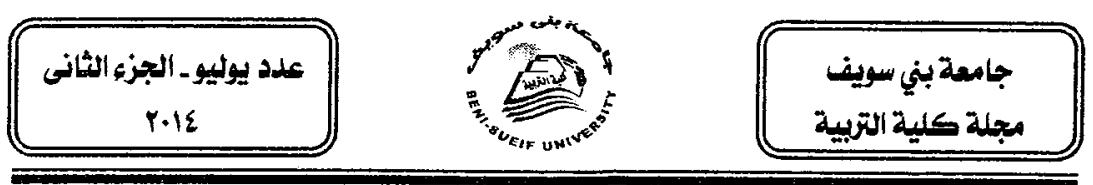

وفعال قادر على التعامل مع احتياجات سوق العمل ومدى قدرتهم على

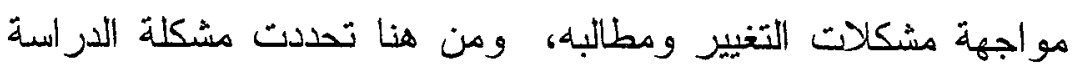
في مدى معرفة خريجي الجامعات السعودية بالموارد التعليمية المفتوحة وأهميه استخدامها وإيراز المعوقات التي تواجه نطبيقها بالإضافة إلى الفرص والتحديات المتاحة أمامها لتطوير وتحسين مخرجات عملية التعليم والتعلم . أسئلة الاراسة:

تمثلت مشكلة الدراسة في عدة أسئلة وهي كالآتي: 1.ما مدى معرفة خريجي الجامعات السعودية بالموارد التعليمية

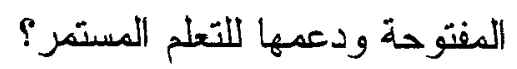
r.ما فوائد استخدام الموارد التعليمية المفتوحة من قبل خريجي

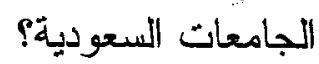
ب.ما أبرز المعوقات التي تواجهها الموارد التعليمية المفتوحة

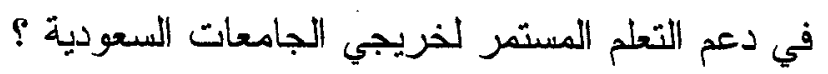

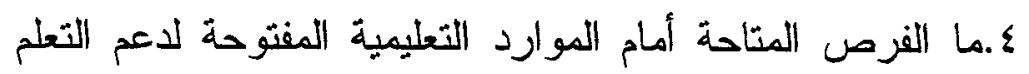
المستمر لدى خريجي الجامعات السعودية؟

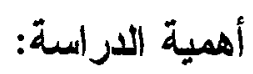
من المأمول أن الدراسة الحالية قد تقيد الجهات الآتية:

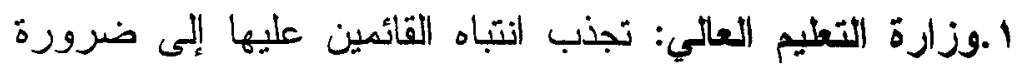

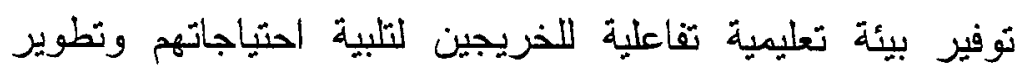
كفاءتهم المهنية مما يساعد في تتمية المجتمع. 

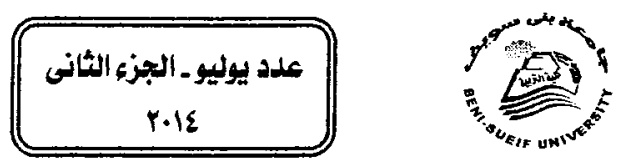

r.الخريجين: من خلا تثجيعهم على مو اصلة نعلمه ومعرفه كل

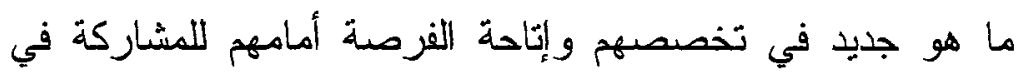
نشر المعرفة الحرة.

ب.الباحشين: تفتح هذه الدراسة الطريق لإجراء بحوث أخرى تهذف إلى الكثف عن أفضل أنماط التعلم المستمر التي يمكن تطبيقها في لإني تطوير نوعية التُطيم العالي من خلال توظيف الموارد التعليمية المفتوحة لدى خريجي جامعات الملكة العربية السعودية.

$$
\text { حدود الاراسة: }
$$

• الحدود الموضوعية: الموارد التعليمية المفتوحة لدعم التعلم المستمر لاى خريجي الجامعات السعودية:الواقع و المأمول . مالحدود المكانية: جامعات الملكة العربية السعودية.

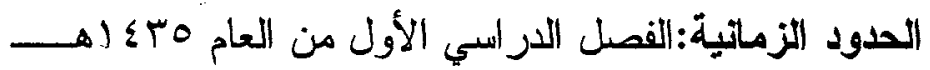

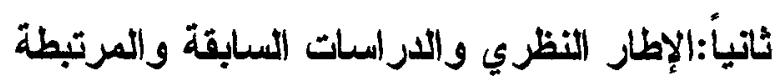
المحور الأول: الموارد التعليمية المفتوحة (OER)

\section{Open Educational Resources}

1 امفهوم الموارد التعليمية المفتوحة ونشأتها

يسهم التعليم في توفير المهارات اللازمة للتمبة الاقتصادية

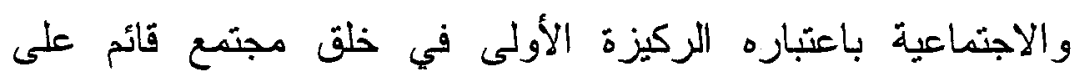

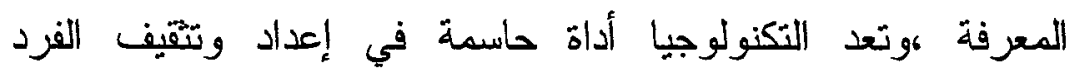

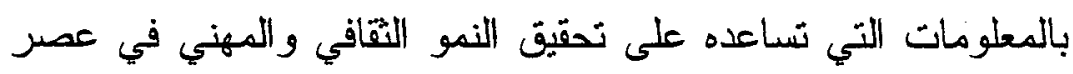

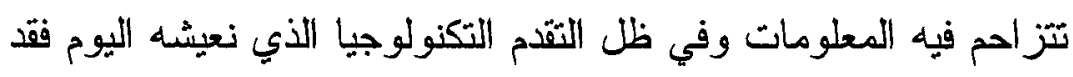

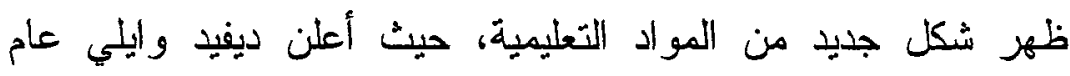

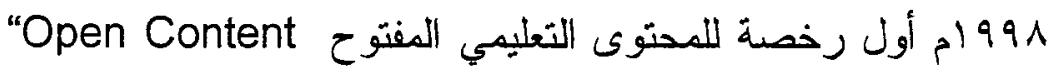




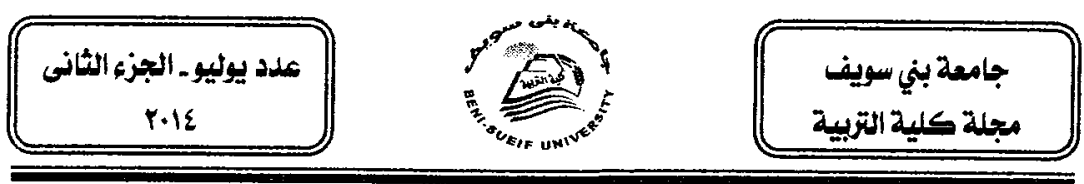

واستتد على أن المحتوى التعليمي ينبغي أن يكون Project" (OSI).

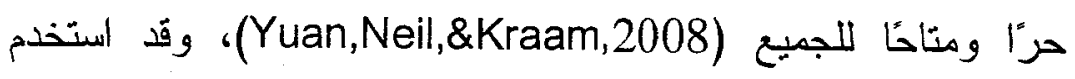

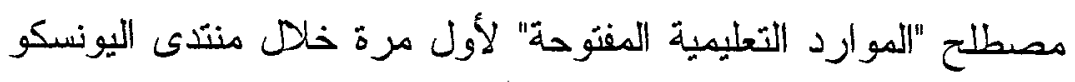

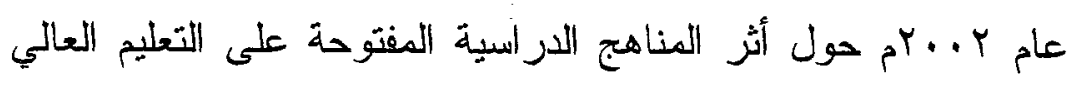

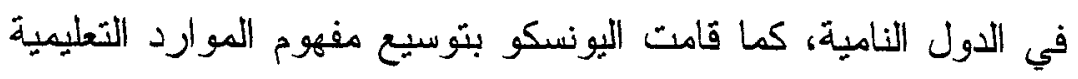

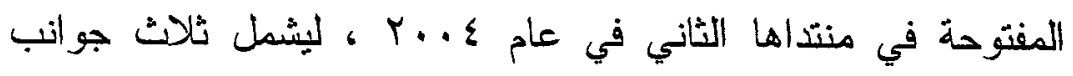

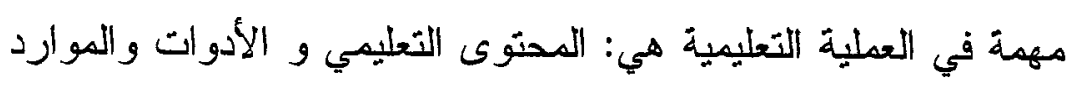

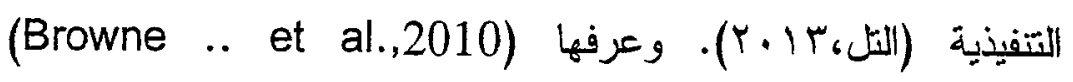
بأنها"موارد تعليمية رقمية موجودة على الانترنت في المجال العام

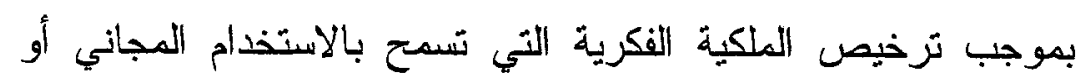
إعادة تحديد الأهداف من قَل الآخرين"، وذكرت (Breck,2007)

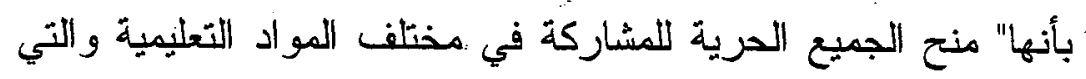
تجعل من المكن طباعتها وقراءتها عن طريق الانترنت دون أي لئي

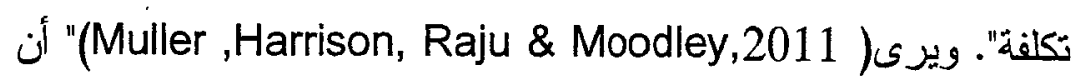
الخيط المشترك بين النعريفات هو "إمكانية استخدام المحتوى التعليمي

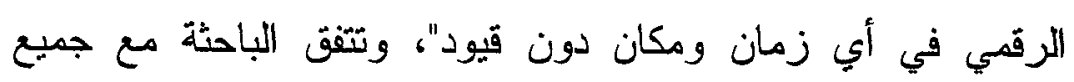

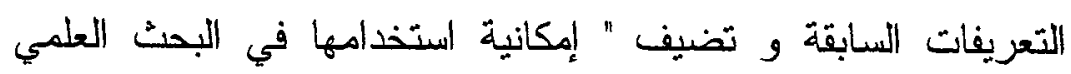
بهدف تحسين عملية التعليم وضمان استمر اريته". r. بفوائد الموارد التعليمية المفتوحة

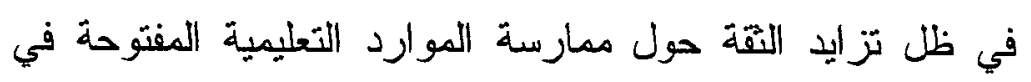

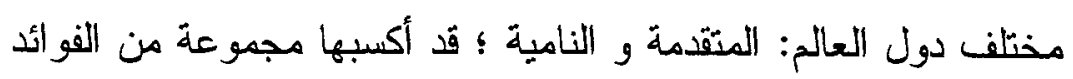
كما بذكرها Williams (2010) عن ما ورد في منظمة التحاون

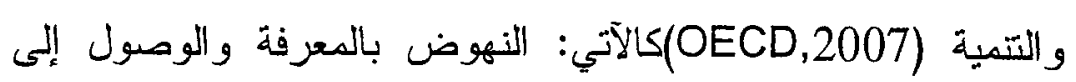




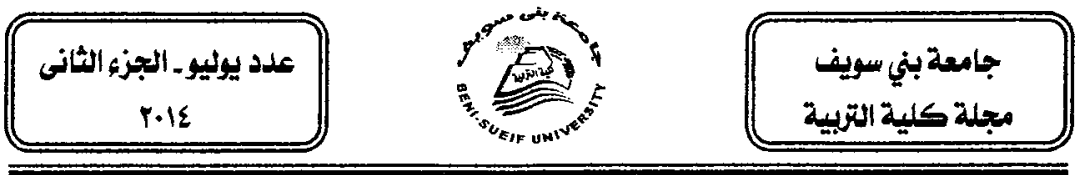

المعلومات بحرية، مشاركتها الواسعة في التعليم العالي عن طريق تمكن المتعلمين من إكمال دراستهم في أي وقت وأي مكان، قدرتها على جذب الخريجين و المتعلمين وتشتجيعهم للتعلم مدى الحياة، تزيد

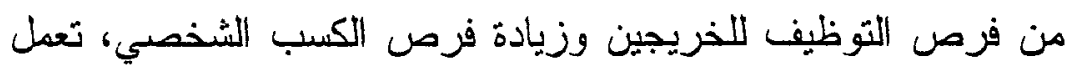
على سد الفجوة بين التعليم النظامي وغير النظامي، وتضيف: ( Yang

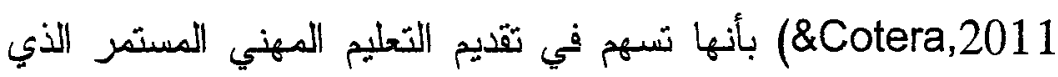
يعمل على إصلاح ونظوير الاقتصاد المحلي في المجتمع.

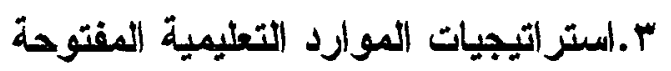

تسعى معظم الدول إلى توفير تعليم ذو معنى عالي الجودة في

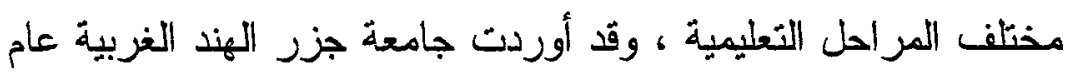

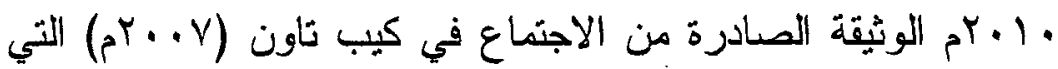
هدفت إلى دعم التعليم العالي وخاصة في البلدان النامية والعمل على فئل تصسين وتطوير نوعية التعليم فيها ، حيث ذكرث ثلاث استراتيجيات من شأنها أن تساعد الفرد على التعلم الذاتي وهي: ا.المعلمين والمتعمين للمشاركة فيها و تشمل: استخدامها ونطويرها، وتبني الممارسات التعليمية التي تتمدور حول الثعاون واكتشاف و إنشاء المعرفة؛ و الدعوة إليها. r.الموارد النعليمية المفتوحة:وهي خاصة بالمؤلفئين والناشرين و إتاحتها بحرية للمستخدمين ويسهل الوصول إليها وترجمتها واستيعابها لمجموعة متتوعة من المنصات التقنية. ץ.سياسة التعليم المفتوح :تتعلق بالمدارس والجامعات والحكومة لمنات بإعطائها أولوية قصوى و اعتمادها . 


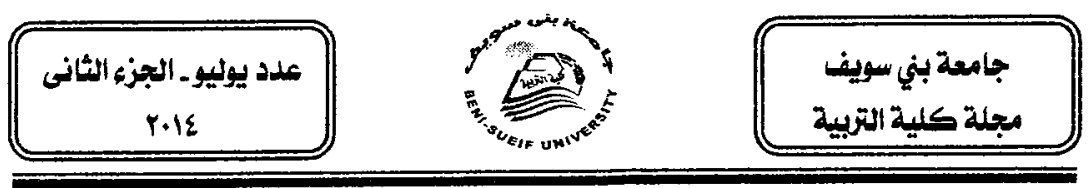

ويرى (Yang \& Cotera,2011) أن هذه الاستراتيجيات

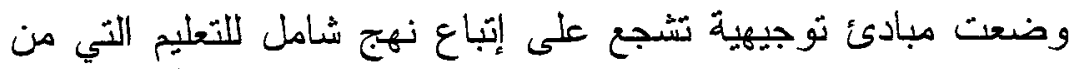

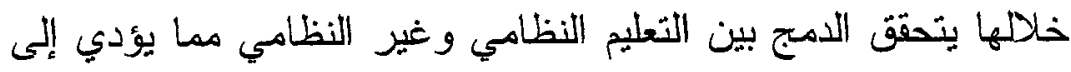
اكتساب معارف جديدة ومهارات من شأنها تحسن نوعية التعليم قادرة على استيعاب مجموعة متنوعة من المنصات الثقنية الحديثة. ؛ ـالتحديات والفرص التي تواجهها

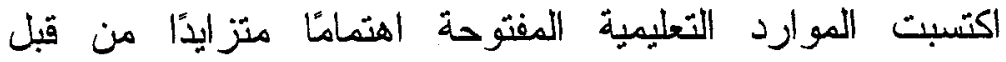

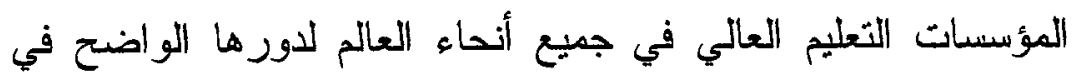
توفير فرص تعليمية تتصف بالمرونة ومساعدتها في تطوير المعرفة

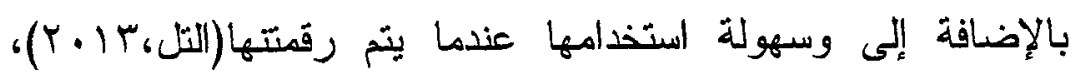

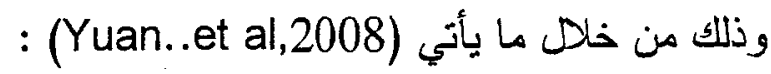

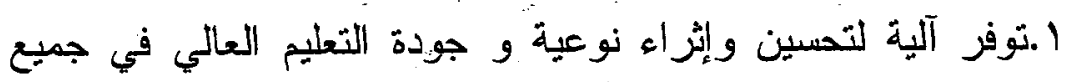

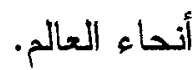
r.بنعزيز عملية التحليم والتعلم في حياة الأفراد.

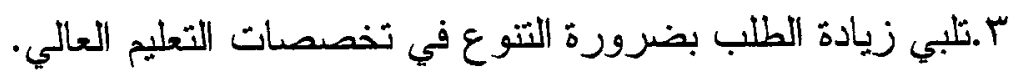

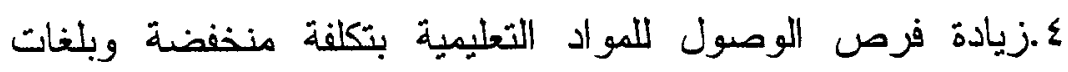

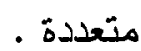
•.تخلق رأس المال الفكري القادر على الابتكار والإبداع في مختلف

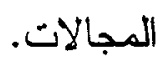

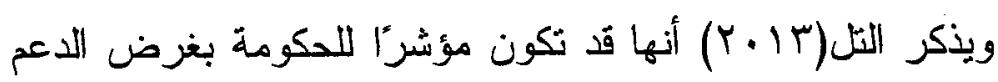

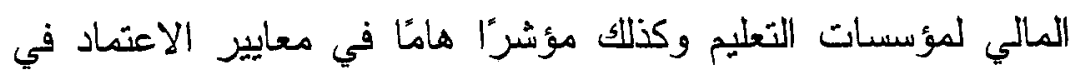

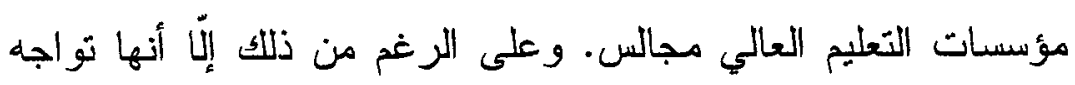

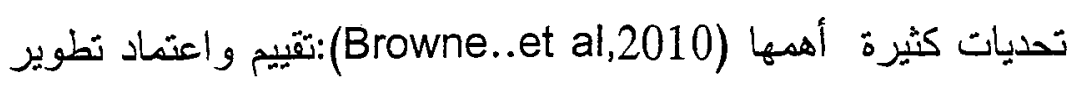




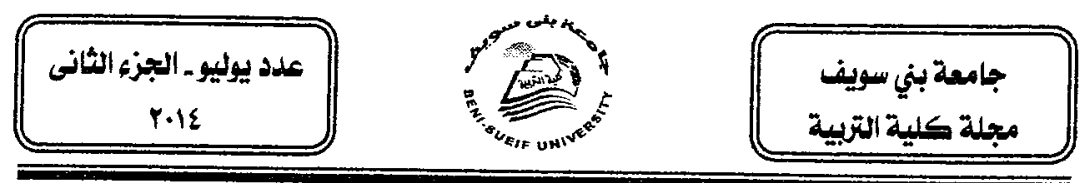

المناهج، ضبط سياسة إدارة المحتوى، الملكية الفكرية، الاستدامة

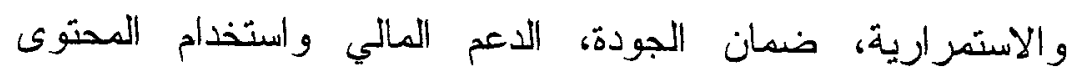
التعليمي ، إلا أن التحدي الأكبر هو تقبل الانفتاح : "الثقافات الخارجية المختلة"، التي تتطلب التغيير في السياسات والآليات لإدارة المؤسسة التعليمية ، وذلك السماح باستخدام مشاركة أعضاء الهيئة التدريسية في

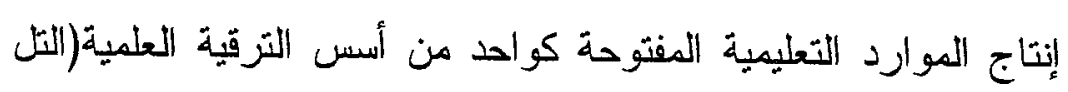
$\cdot\left(r \cdot 1 r_{6}\right.$

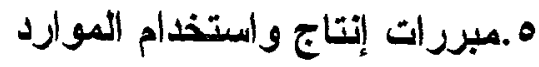

توجد العديد من المواد والأنشطة التعليمية المتاحة على شبكة

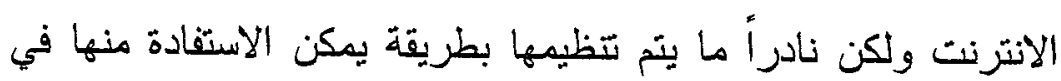

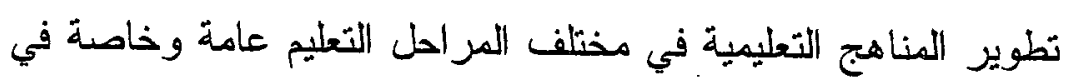
التعليم العالي، مما دفع بعض الدول مؤخزًا إلى استخدام الموارد

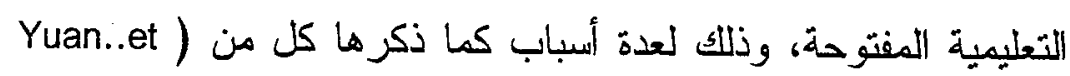
(Falconer, Littlejohn, McGill, \& Beetham,2014) و وهي (al,2008 كالآتي: ا.عدم وجود سياسات تؤكد مجال الابتكار ات التعليمية والتربوية في التغييز التتظيمي للمؤسسات التحليم العالي.

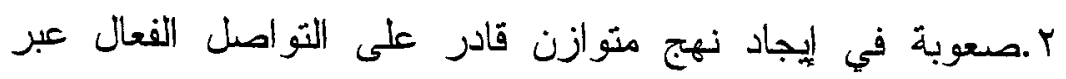
الثقافات المختلفة. r.الافتقار إلى التواصل والتعاون بين المؤسسات والمطورين من المعلمين و الطلابب. ع .تشجيع المؤسسات الدولية لتمويل مشاريع جديدة قادرة على إنتاج مصادر تعلم. 


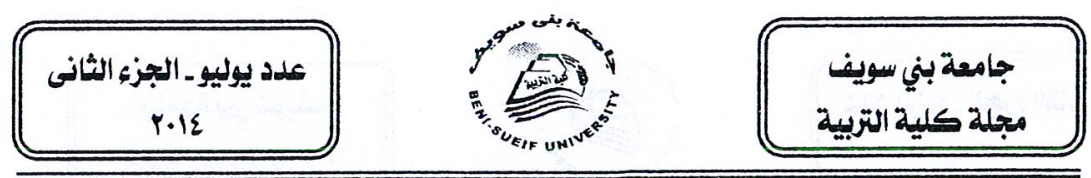

ه.إيجاد مسنودع رقمي دائم منعدد اللغات متعدد الوسائط . ويضيف (Yang \& Cotera,2011) أن في استخدام وإنتاج الموارد التعليمية المفتوحة حاجة منجددة لبناء مدينة نعليمية نسمح بتبادل أفضل الخبرات والممارسات لإنشاء نعلم ذي نظام جديد يساعد على تجسيد التعلم مدى الحياة ليجمع بينه وبين التعليم الأكاديمي . 7 . هستقبل تطبيق الموارد في المملكة تسعى المملكة العربية السعودية باستمرار إلى تطوير التحليم بجميع

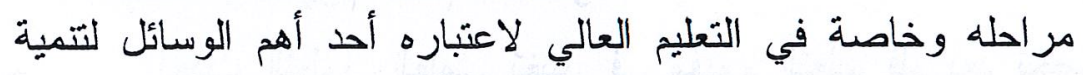
الموارد البشرية فيها، وبالنظر إلى التغيرات السريعة التي تحدث في

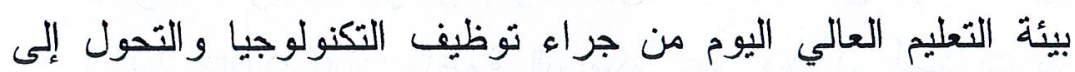
عصر أطلق عليه "عصر المعرفة "،حرصت على جعل الجزء الأكبر

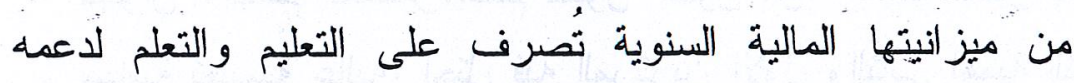
ولنطويره وتوفير التّريب المهني المناسب لخريجيها، ويكمن الهرف وراء مشروع "آفاق" الوطني الذي أطلق في عام هـ م. بام هو نوفير سرعة عالية في شبكة الاتصالات القائمة على الإنترنت لإنتاج ونشر

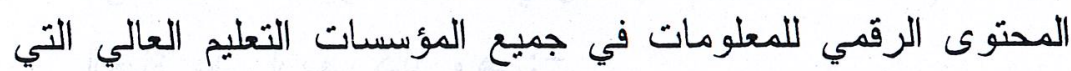
تملك مكتبات الكترونية لنشجع بدورها حركة التعليم المفتوح

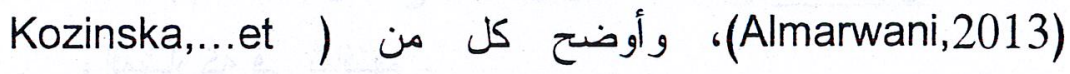
al.2010 ) و (Sclater,2010) أن في الموارد التعليمية المفتوحة مبادرة جديدة تساعد في تبني التغبرات المستقبلية التي تواجهها مؤسسات التعليم العالي والتي تتعلق في القضاء على الأمية بتشجيع التحلم الذاتي ، وتوفير فرص مهنية مختلفة لجميع الخريجين بالإضافة إلى خفض الطلبات المتزايدة على الدراسات العليا وكسر جميع برئ برئ 


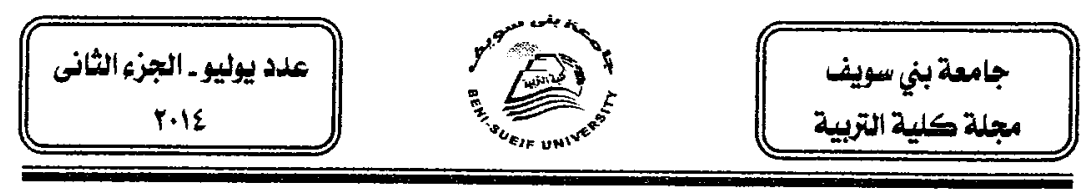

الحواجز الجغرافية بإنشاء جامعه بدون جدران وهو ما تسعى إليه الدول المتقدمة لارتباط التنمية المهنية إلى حد كبير بالتنريب واكتئساب

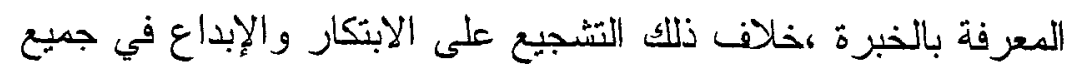

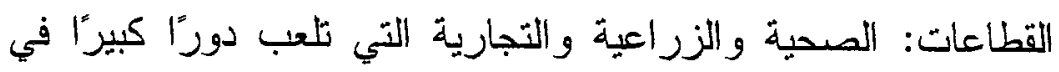
النمو الاقتصادي والاجتماعي في الدولة. المحور الثاني:التعلم المستمر ا.قلسفة و مفهوم التعلم المستمر المبنم أحدث التطور العلمي تغيير في مفهوم النعليم فلم يعد تحصيل العطيل

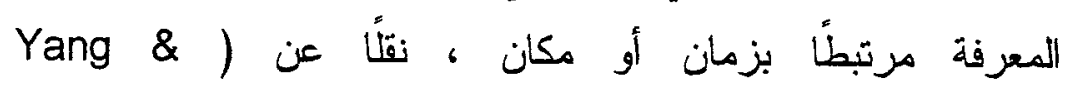

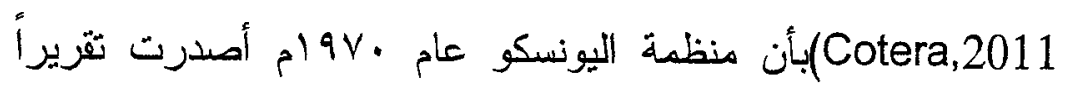

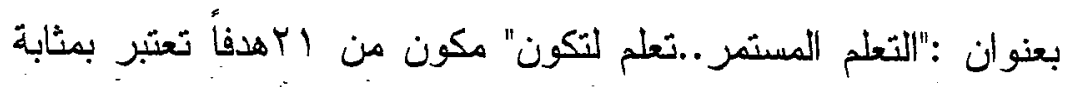

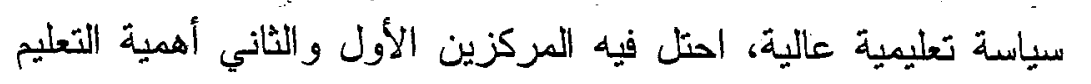

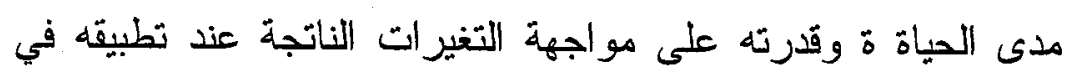

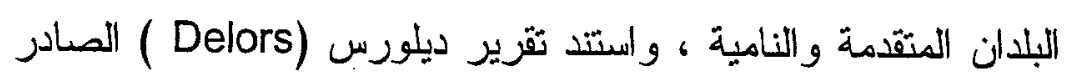

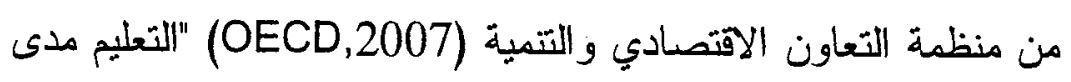
الحياة" على أربع ركائز وهي:-

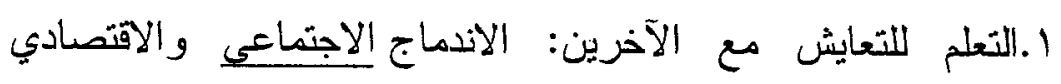
و المشاركة في ثقافتهر .

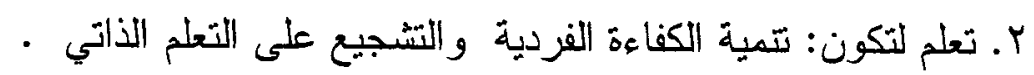

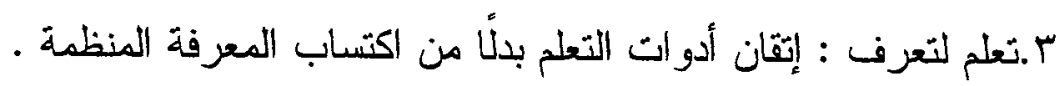

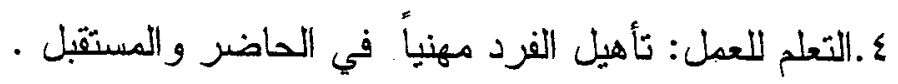

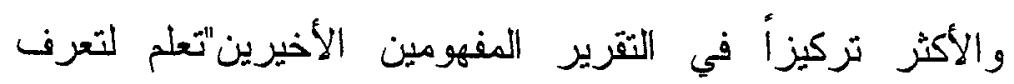

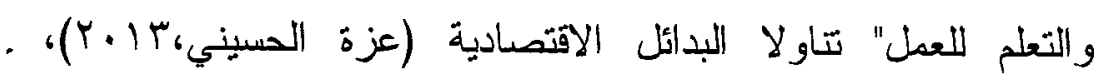



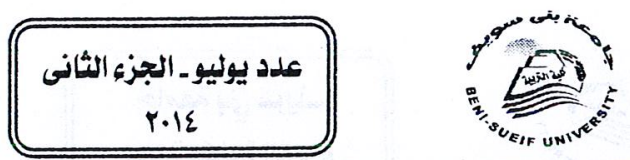

جامعة بني سيفيف

مجلة كلية التربية

Lifelong و للتعليم المستمر عدة مصطلحات : التزبية مدى الحياة و Continuing. Education و التزبية المستمرة Education التربية الدائمة Education Permanent و التعلم المستمر Continuous Learning مستمرة لا يقتصر بمرحلة عمرية أو دراسية دعينة، وهو ما أكد عليه جون ديوي في هذا النوع من التعلم بأنه" التعلم الحقيقي يأتي بعد أن

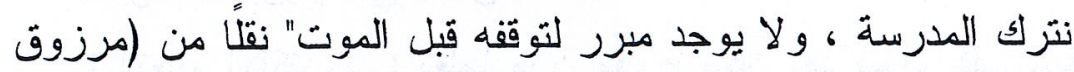

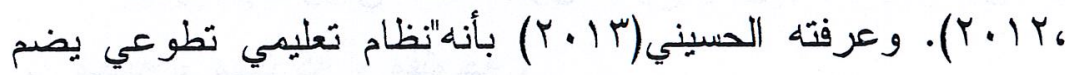
جميع أطراف التنظيم المدرسي والمجتمع المحلي من أجل نكوين مجنمع للتعلم ينشارك أفزاده اكتساب وتبادل المعارف و المهار ات و الخبرات اللزمة لمواصلة أدوارهم الحياتية والمهنية بعد ذلك، مع مر اعاة النوازن بين احتياجات المتعلمين مدى الحياة ومنطلبات اقتصاد

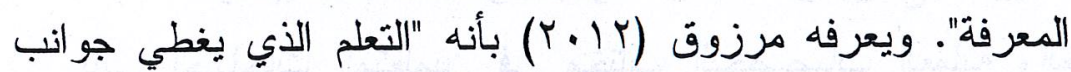

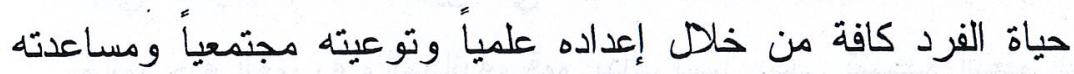

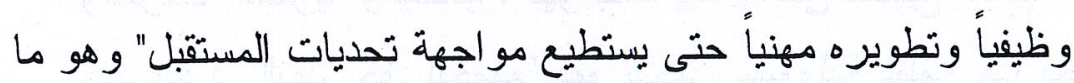
تبنته الباحثة كونه أكثر ملاعمة لطبيعة الدر اسة.

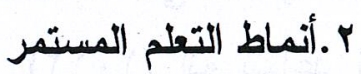
برى (Hussain,..etc,2013 ) التعلم المستمر بأنه نشاط تعليمي يمكن تطبيقه خارج التعليم النظامي الذي يسعى إلى الربط الايجابي بين احتياجات وتطلعات الأفراد مع الأشطة التعليمية ، وعبر عنه بمفهوم تعليم الكبار الذي يؤكد على توفير الفرص التعليمية للبالغين بعد التوقف عن التعليم الرسمي منل : تاركي المدرسة ، و العاملين

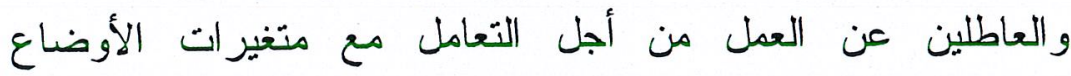




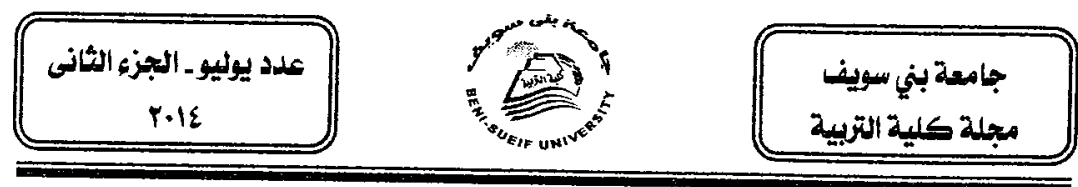

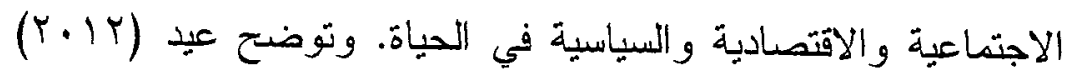
أبرز أنماط التعلم المستمر فيما بأتي:-

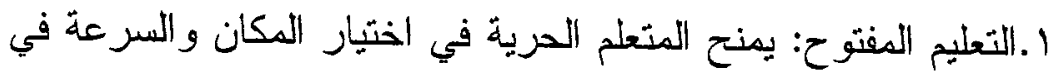
تعلمه . ץ.التحليم عن بعد: اتصال المعلم بطلابه عبر شبكة الانترنت أو بالمر اسلة البريدية في أماكن مختلفة .

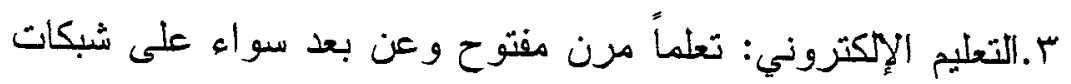
مغلقة أو مشتركة أو مفتوحة . ؛.التعليم الافتراضي: جزء من الإكتروني يرنتئ على الشبكات

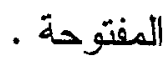

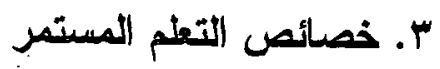
يُقدم التعلم المستمر مجموعة واسعة من برامج التدريب التئي تلبي احتياجات المتعلمين في مختلف التخصصات العملية والعلمية

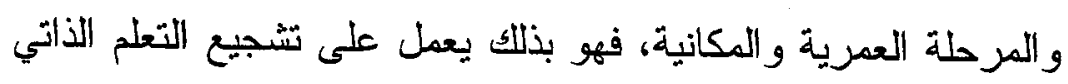

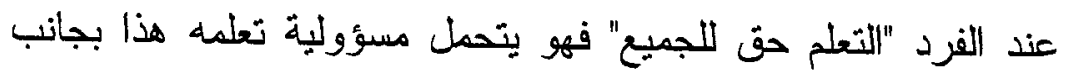

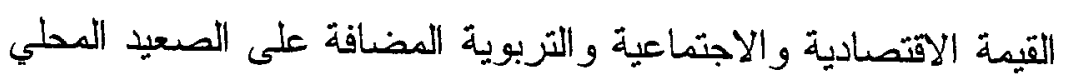

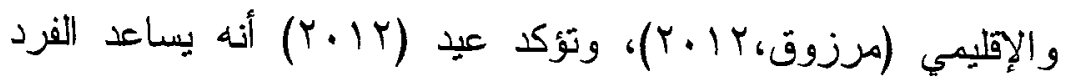

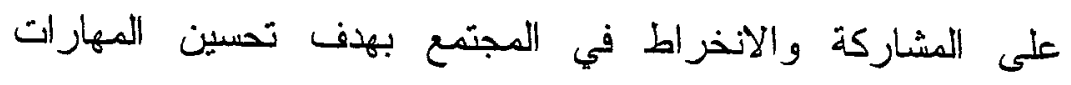

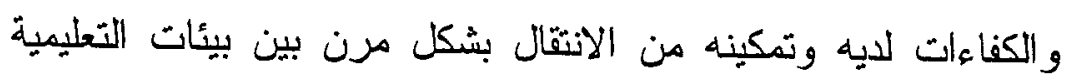

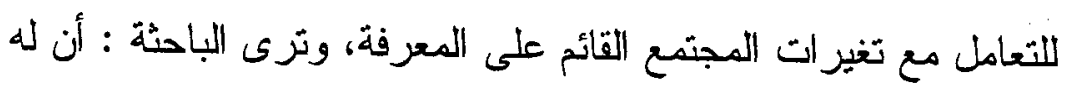

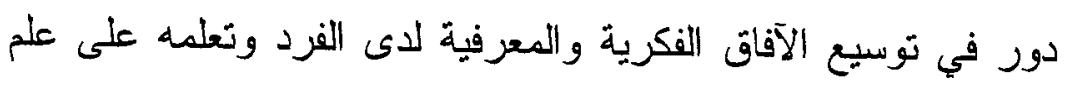
لما يدور من حوله عن طريق اكتسابه معلومات ومعارف جديدة . 

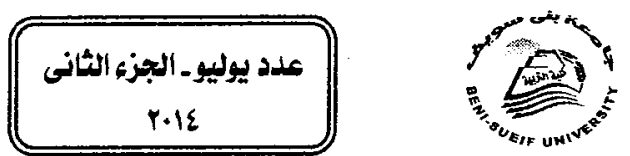

جامعة بني سويف

مجلة كلية التربية

ع. دور مؤسسات التعليم العالمي في دعم التعم المتمر عالمياً

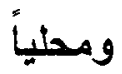

في الفترة الأخيرة من القرن الب تتافست مؤسـسات التعليخ

العالي في معظم دول العالم في إنشاء وحدات للتعليم المستر لكونه

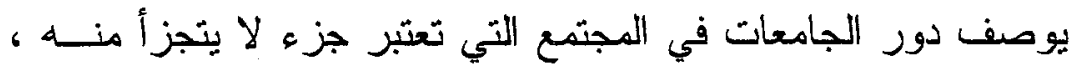

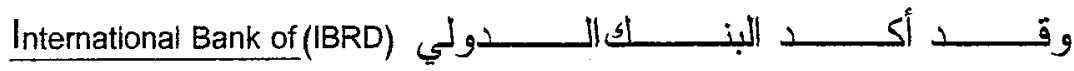

Reconstruction and Development

لمواكبة التغيرات في سوق العمل فمعظم المهن ثتغير بمرور الوقت ،

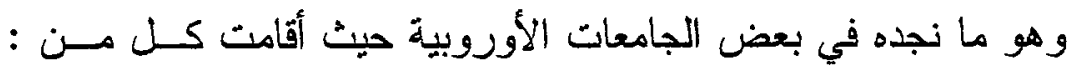

جامعة تكساس وجامعة نيويورك وجامعة مــونتيري فــي المكسيك

بالتركيز على إنشاء مر اكز تدعم التطور المهني والتعلم المستمر ليكون

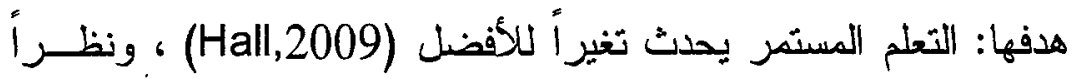

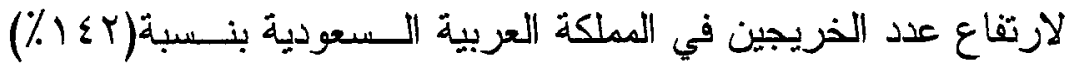

نظمت وزارة التعلم العالي ورشة عمل بعنوان (تعزيز الوظيفة الثالثـة التهة

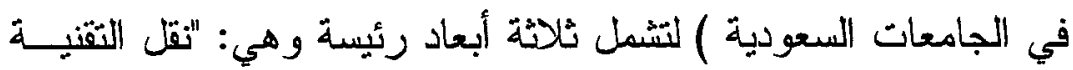

و الابتكار، التعلم المستمر ، المشاركة المجتمعية" والتي تشكل المهنــة

الثالثة للجامعة بجانب التدريس و البحث العلمي، فالجامعات الـسعودية

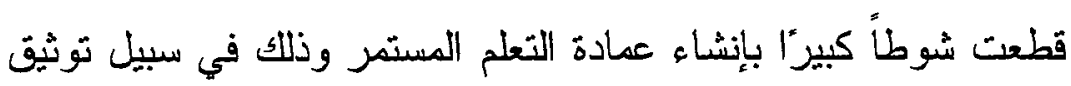
العلاقة بين الجامعة و المجتمع وخدمته بكافة شر ائحه، ولخلق التتـافس

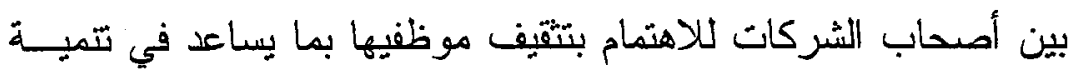
رأس المال البشري و الفكري (وزارة التعليم العالي،با. بـ). 


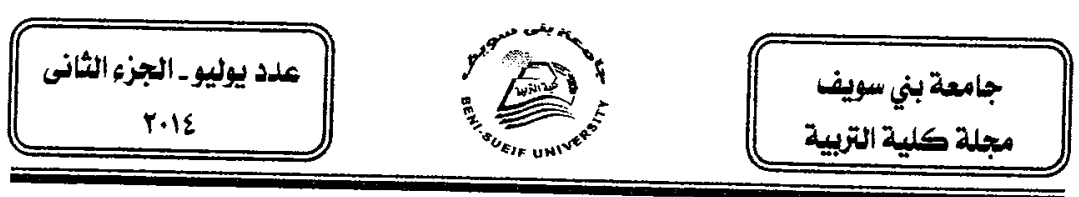

\section{منهجية الار اسة وإجر اءواتها ا.منهج الدراسة:}

اتبعت الدراسة الحالية المنهج الوصفي التحليلي، لاعتماده على التها

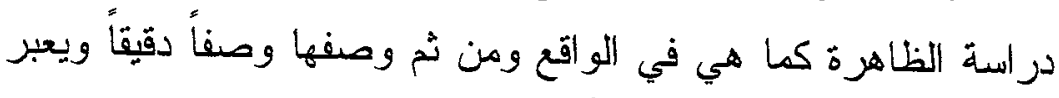
عنها تعبيرأ كيفياً أو تعبير أ كمياً.

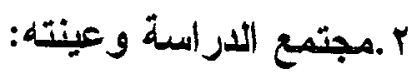

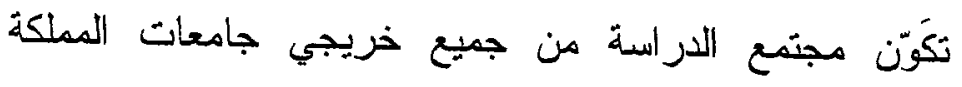

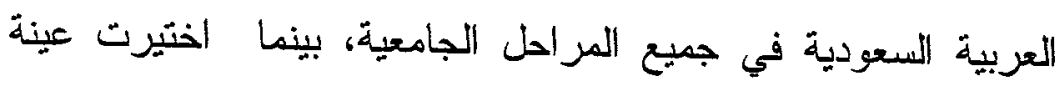

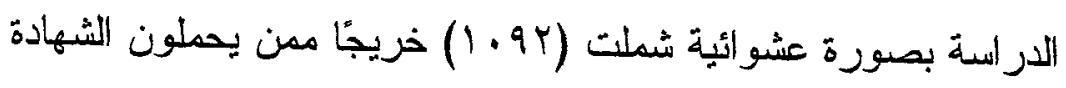

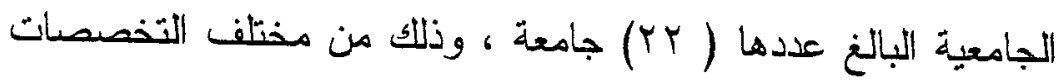
العلمية ، وفيما يأتي الخصائص الديموغرافية لأفراد عبيذة البراسة: • توزيع أفراد العينة حسب الجنس:

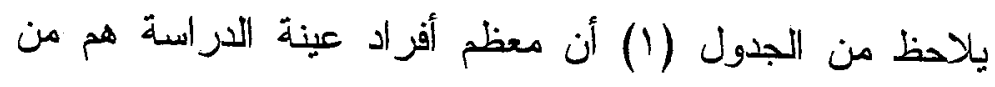

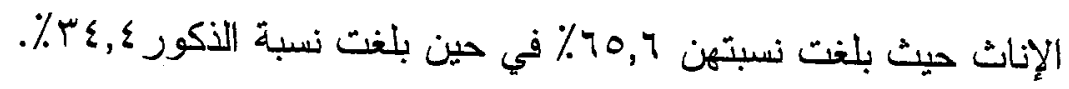

\begin{tabular}{|c|c|c|}
\hline$\%$ & اللعدد & الجنس \\
\hline$r \varepsilon, \varepsilon$ & rV & ذكر \\
\hline 10,1 & V17 & أنثى \\
\hline $1 \ldots$, & 1.94 & المجموع \\
\hline
\end{tabular}

• توزيع أفراد العينة حسب سنة التخرج:

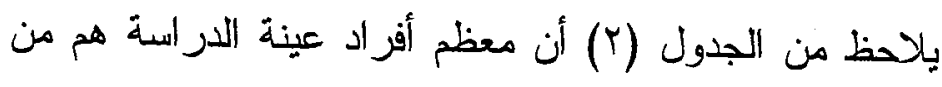

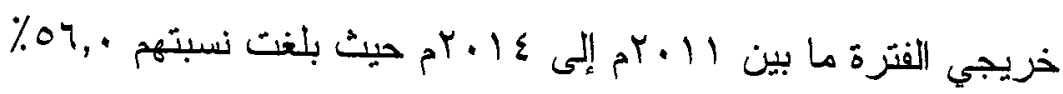



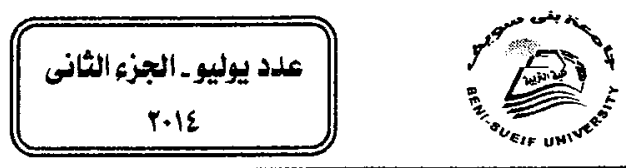

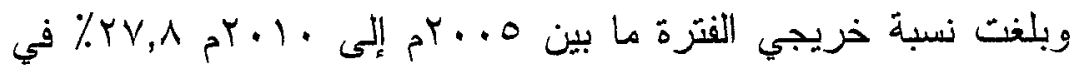

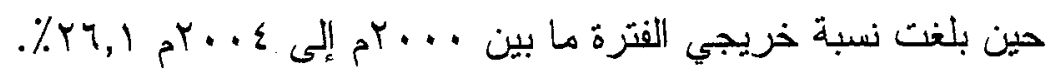

\begin{tabular}{|c|c|c|}
\hline$\%$ & العلد & سنة التخرج \\
\hline 17,1 & 187 & $\rho^{r} \ldots \varepsilon-r \ldots$ \\
\hline$r V, \Lambda$ & $r \cdot \varepsilon$ & $p^{r}+1 .-r \ldots o$ \\
\hline $07,$. & צr & $p^{r+1} \varepsilon-r+11$ \\
\hline $1 \ldots$, & 1.94 & المجموع \\
\hline
\end{tabular}

• توزيع أقراد العيزة حسب المرحلة الجامعية:

يلاحظ من الجدول (ب) أن معظم أفر اد عينة الدراسة هم من

الحاصلين على البكالوريوس حيث بلغت نسبتهم r, با7\% وبلغت نسبة

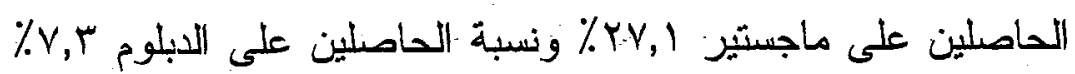
في حين بلغت نسبة الحاصلين على الدكتور اه ع,ـ ٪. جدول (ب) توزيع أفراد العينة حسب المرحلة الجامعية

\begin{tabular}{|c|c|c|}
\hline$\%$ & الاعدد & المرحلة الججامعية \\
\hline$Y, 71$ & 741 & بكالوريوس \\
\hline$r, v$ & $\wedge$. & دبلوم \\
\hline $1, r V$ & ห९9 & ماجستير \\
\hline$\varepsilon, \varepsilon$ & $\leqslant \wedge$ & دكتور اه \\
\hline $1 \cdots, \cdot$ & $1.9 r$ & المجموع \\
\hline
\end{tabular}

• توزيع أقراد العينة حسب الجامعة التي تم التخرج منها: يلاحظ من الجدول (ع) أن معظم أفراد عينة اللراسة هم من خريجي جامعة الملك عبد العزيز حيث بلغت نسبتهم ^,اءع) وبلغت نسبة خريجي جامعة أم القرى ؟, ، ( ٪ ونسبة خريجي جامعة الملك 

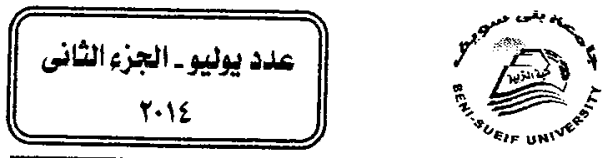

سعود ^,^٪ و نسبة خريجي جامعة نجران وخريجي جامعة الدمام

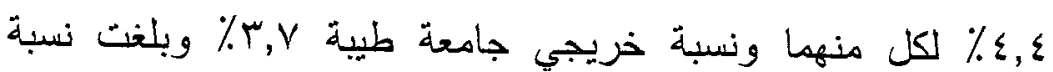

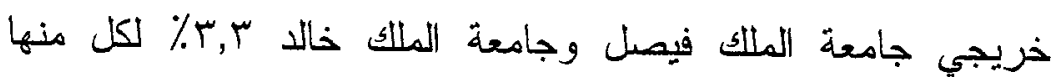

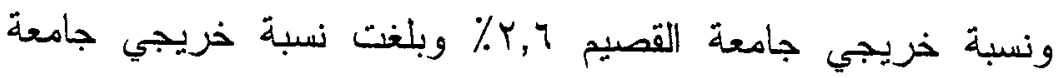
جازان وجامعة الطائف وجامعة الإمام محمد بن سعود الإسلامية

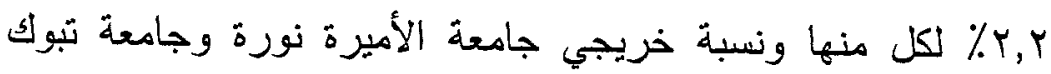

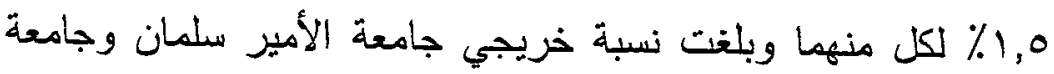
الباحة والجامعة الإسلامية 1,1\% لكل منها ونسبة خريجي جامعة الأمير محمد بن فهر V, • ٪ في حين بلغت نسبة خريجي جامعة الجوف وجامعة الأمير فهذ بن سلطلان وجامعة الخرج ع, ، ٪ لكل منها. جدول (؛) توزيع أفراد العينة حسب الجامعة التي تم التخرج منها وجها

\begin{tabular}{|c|c|c|}
\hline$\%$ & 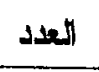 & الجامعة التي تم التخرج منها \\
\hline$\Lambda, \Lambda$ & 94 & جامعة الملك سعود \\
\hline$\Lambda, \leqslant 1$ & \&० & جامعة الملك عبد المزيز \\
\hline $7,1$. & 119 & جامعة أم القرى \\
\hline$r, r$ & $r q$ & جامعة الملتك فيصل \\
\hline$\varepsilon, \varepsilon$ & $\leqslant \wedge$ & جامعة نجران \\
\hline Y,, & 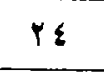 & جامعة جازلن \\
\hline$Y, Y$ & rA & جامعة حائل \\
\hline$\{, \varepsilon$ & $\varepsilon \wedge$ & جامعة اللمام \\
\hline$v, \cdot$ & $\wedge$ & جامعة الأمير محمد بن فها \\
\hline$Y, r$ & $Y \wedge$ & جامعة القصيم \\
\hline$\varepsilon, \cdot$ & $\leqslant$ & جامعة الجوف \\
\hline$r, r$ & r & جامعة الملاك خالد \\
\hline
\end{tabular}




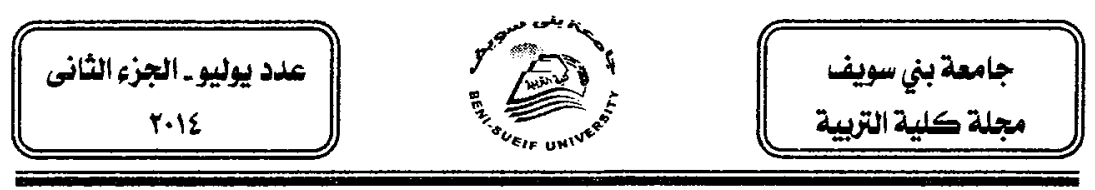

\begin{tabular}{|c|c|c|}
\hline$\vee, r$ & $\varepsilon$ & جامعة طيبة \\
\hline 1,1 & Ir & جامعة الأميز سلهان \\
\hline$Y, Y$ & Y\& & جاهعة الطائف \\
\hline 0,1 & 19 & جامعة الأميرة نورة بنت عبد الرحمن \\
\hline 1,1 & ir & جامعة الباحة \\
\hline$r, r$ & $r \leqslant$ & جامعة الأمام محمد بن سعود الإسلامية \\
\hline$\varepsilon, \cdot$ & $\varepsilon$ & جامعة فهر بن سلطان \\
\hline 1,1 & Ir & اللجامعة الإسلامية بالمدينة المنورة \\
\hline$\varepsilon,+$ & $\varepsilon$ & جامعه الذرج \\
\hline 0,1 & 17 & جامعة تبوك \\
\hline$\% 1 \cdot$, & 1.94 & المجبوع \\
\hline
\end{tabular}

توزيع أفراد العينة حسب العمل:

يلاحظ من الجدول (0) أن معظم أفراد عينة الذراسة هم من فئن

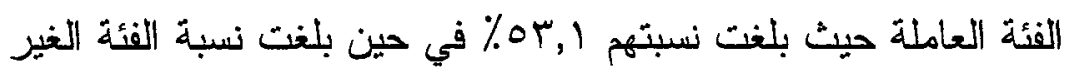

عاملة q,

\begin{tabular}{|c|c|c|}
\hline \multicolumn{3}{|c|}{ جذول (•) توزيع أفراد العينة حسب العل } \\
\hline$\%$ & اللعدد & العطل \\
\hline 04,1 & os. & نعم \\
\hline$\leq ৭, q$ & OlY & ע \\
\hline$\% 1 \ldots$, & 1.94 & 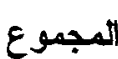 \\
\hline
\end{tabular}

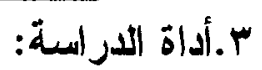

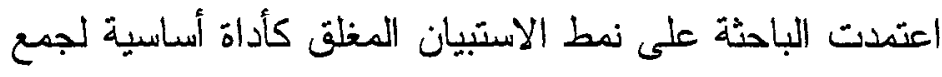

البيانات المطلوبة للإجابة عن تساؤلات الدراسة وتحقيق أهدافها

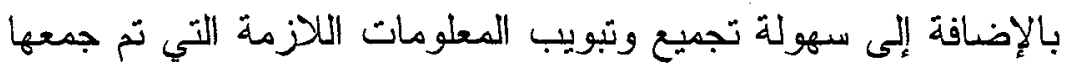



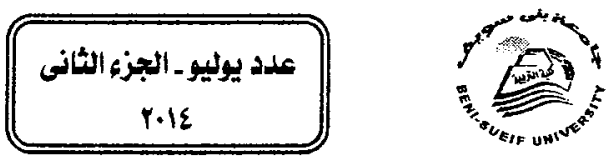

من خلاله، وبالرجوع إلى الأدبيات والدراسات العربية والأجنبية

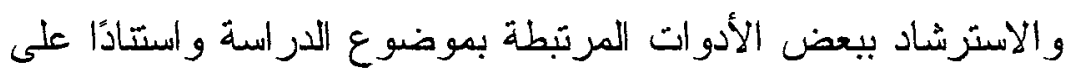
آراءنخبة من أساتذة وتربويين في مختلف الجامعات المحلية والإقليمية، تمت صياغة مفردات الانتبيان بناء على الضوابط العامة لكتابته، ومن

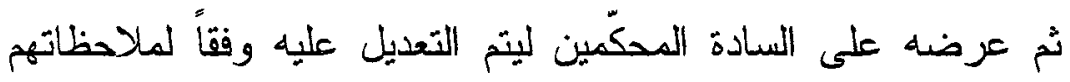
الواردة و العمل بها.

الصدق و الثبات لأداة الدراسة:

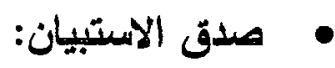

قامت الباحثة بعرض الاستبيان على مجموعة من السادة المحكمين المتخصصين في مجال نكنولوجيا التعليم وذلك لإبداء آرائهم

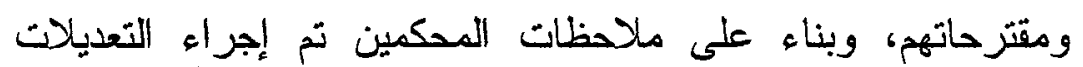

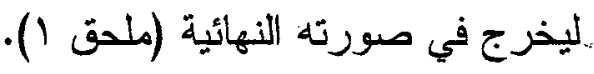

$$
\begin{aligned}
& \text { ثبات الاستبيان: }
\end{aligned}
$$

استخدت الباحثة للتأكد من ثبات الاستبيان معادلة ألفا كرونباخ (Alpha Cronbakh) وذلك بحساب معاملات الاتساق

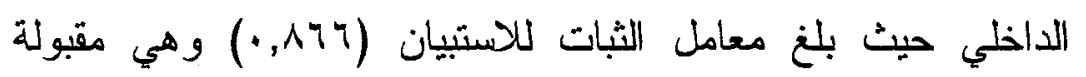
إحصائيًا لاستخدام الانتيبيان كأداة للقياس.

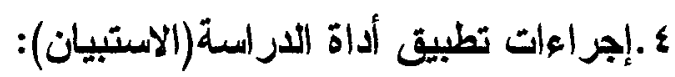

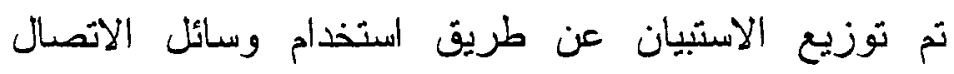

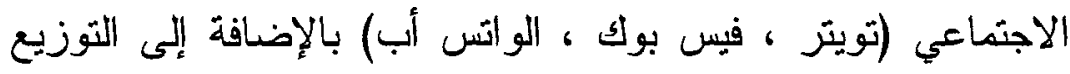
الورقي على بعض خريجي الجامعات ممن تمكنت الباحثة الوصول

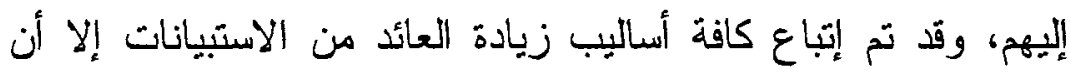

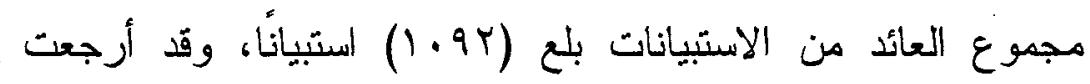




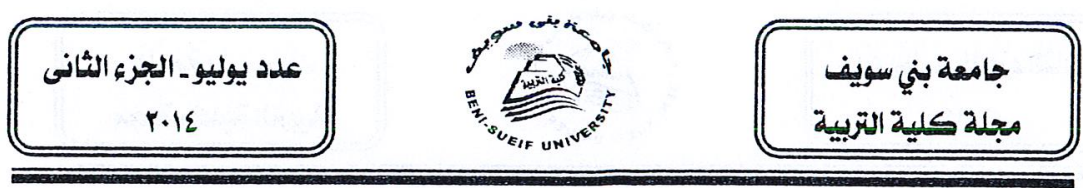

الدراسة ذلك لصعوبة الوصول إلى جميع الخريجين وتشتتهم في مناطق جغر افية متنوعة، وبعد الانتهاء تم تفريغ البيانات و المعلومات إحصائيًا و استخلاص النتائج منه. النتائج و التوصيات إجابة السيؤال الأول:

ما مدى معرفة خريجي الجامعات السعودية بالموارد التعليمبة

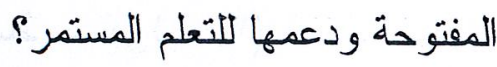

ولإجابة على السؤال الأول ثم تخصيص (· (1) فقرات من

الاستبيان، ودلت النتائج أن قيمة المتوسط العام لمجموع استجابات أفراد عينة الدراسة لمحور مدى معرفة الخريجين بالموارد التعليمية المفتوحة (OER) بلغت (Y,90) ، وهي تشير إلى وجود موافقة على فقرات هذا المحور، حيث حصلت فقرات المحور على منوسطات

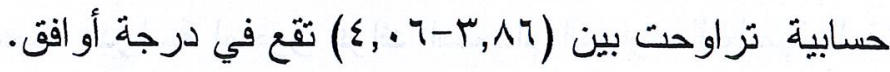

وحصلت الفقرة "تثيح الموارد المفتوحة فرص متتوعة للتحلم

الذاتي و التعاوني" على أعلى منوسط في الموافقة لدى عينة الدراسة

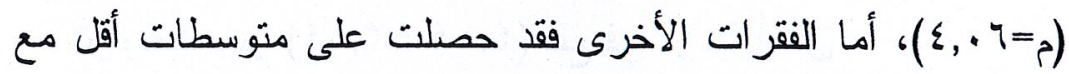
بعض التباين في درجات الموافقة حيث احتلث المرتبة الثانية "توفر الموارد عملية الاتصال و التواصل والتقويم المستمر و الرقابة الذاتية".

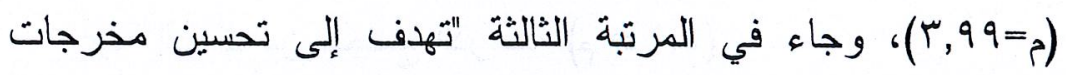

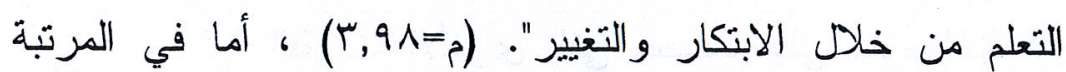
الرابعة "توفر الموارد المفتوحة مناهج جديدة ومنتوعة ثتو افق مع تخصصك" ،"تعمل على تعزيز نشر المعرفة الحرة" و "تدعم الموارد المفتوحة مبادرات على مستوى: "محلي و إقليمي و دولي" (م= 

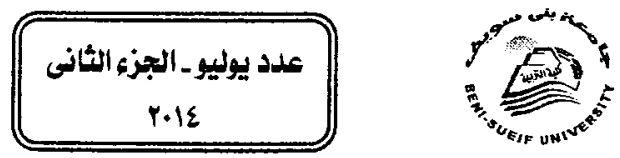

لكل منها، وفي المرتبة السادسة " توفز مناخ تعليمي بسمح بحرية التعبير و المناقشة". (م=90, الموجودة في المناهج الدراسية". (م=.9,\%) ،وجاء في المرنبة الثنامنة

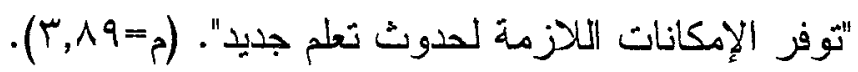

وكان أقل درجة موافقة من وجهة نظر أفراد العينة للفقرة

(تحفظ حقوق الملكية الفكرية وتتيحها من خلا رخص المشاع

$$
\text { الإبداعي) حيث حازت على منوسط حسابي( (؟ی, آ). }
$$

إجابة السؤال الثاني:

ما فو ائد استخدام الموارد التعليمية المفتوحة من قبل خريجي

الجامعات السعودية؟

ولإججابة على السؤال الثاني تم تخصيص (11) فقرة من

الاستبيان، ودلت النتائج أن قيمة المتوسط العام لمجموع استجابات أفر اد عينة الدراسة لمحور فوائد استخدام الموارد الثعليمية المفتوحة (OER) هذا المحور، وحصلت فقرات المحور على منوسطات حسابية

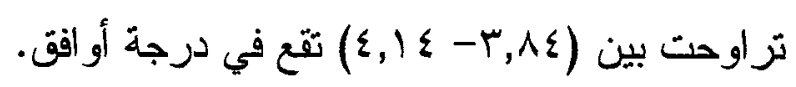

إذ احتلت المرتبة الأولى"تمكند من الاستفادة من خبرات وتجارب الآخرين" فقد حصلت على أعلى متوسط في الموافقة لدى

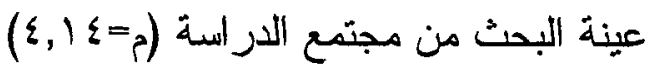
أما الفقرات الأخرى التي حصلت على متوسطات أقل مع مع أن

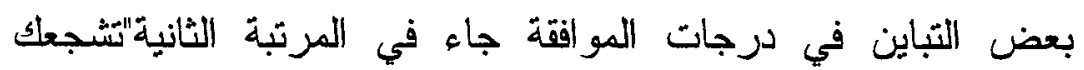

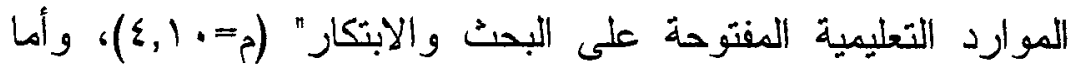

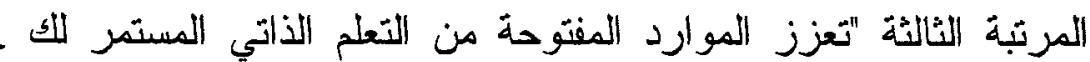



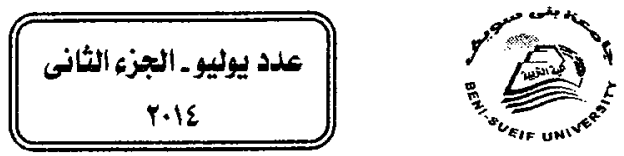

جامعة بني سويف

مجلة كلية التربية

مدى الحياة" (م=9.,.ع) ،تلاها المرتبة الرابعة "تتيح للك الموارد المفتوحة فرص متتوعة للحصول على آخر النطورات العلمية والأكاديمية في تخصصك" و "توفر فرصة الاشتر الك و التعلم في أبي

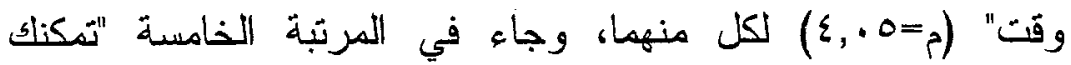
الموارد المفتوحة من اكتساب مهار ات قابلة للاستخدام في مجال تخصصك بثقة وخلفية واعية" (م=1., ؛؛) ، واحتلت المرنبة السادسة "تستخدم الموارد المفتوحة للحصول على دورات في تخصصك"

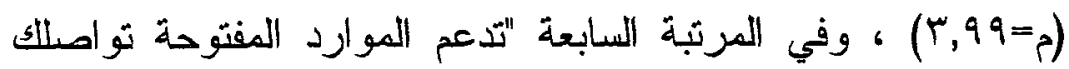

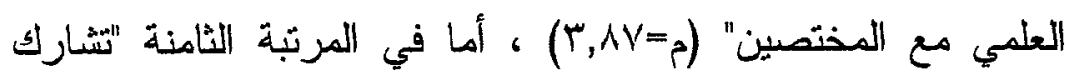

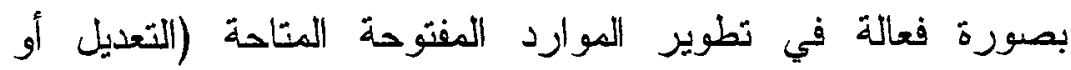

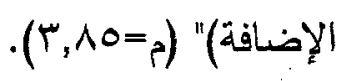

وكان أقل درجة موافقة من وجهة نظر أفراد العينة للفقرتين الثامنة والتاسعة ("تجد صعوبة في الاستفادة من الموارد المفتوحة المتاحة بلغات أخرى" و "تواجه صعوبة في الوصول إلى الموارد المفتوحة الملأئمة للك"و حازت كل منهما على متوسط حسابي عـ, ؟ب). إجابة السيؤال الثالث: ما أبرز المعوقات التي تو اجهها الموارد التعليمية المفتوحة في دعم التعلم المستمر لخريجي الجامعات السعودية ؟ ولإججابة على السؤال الثالث تم تخصبص (11) فقرة من الاستبيان، ودلت النتائج أن قيمة المتوسط العام لمجموع استجابات

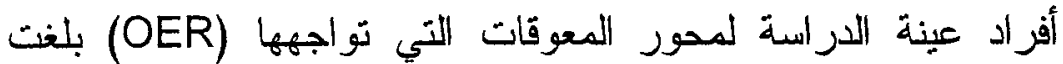
(T,97) ، وهي تشير إلى وجود موافقة على فقرات هذا المحور، حيث 


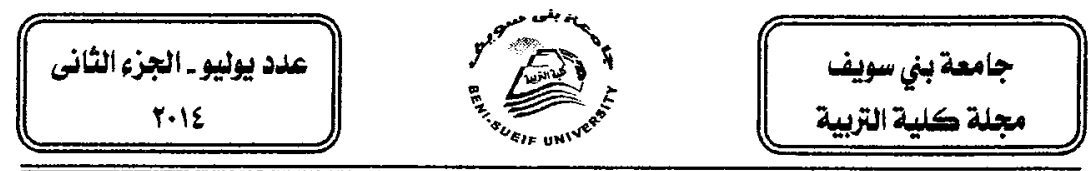

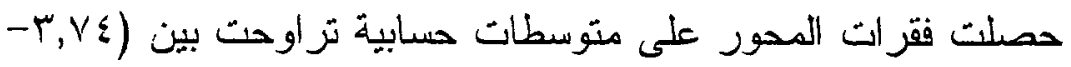

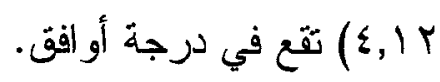

وقد حصلت الفقرة "عدم دعمها من قبل الدعاية والإعلام

بأهمينها للخريجين" على أعلى متوسط في الموافقة لاى عينة البحث

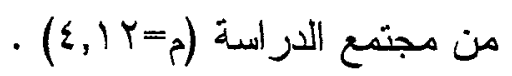

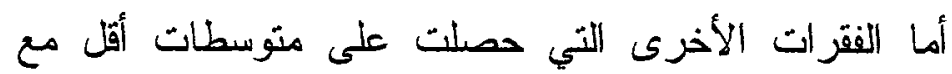

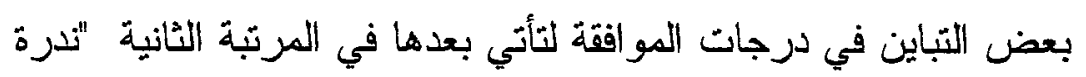

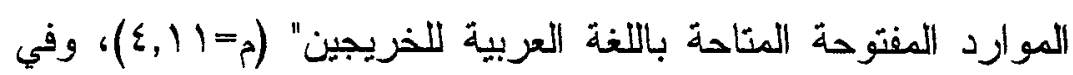

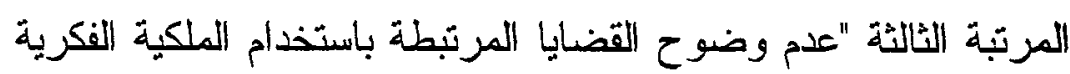

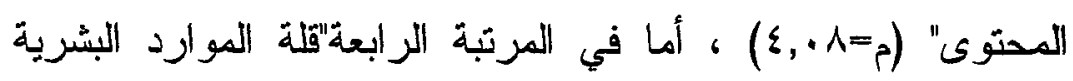

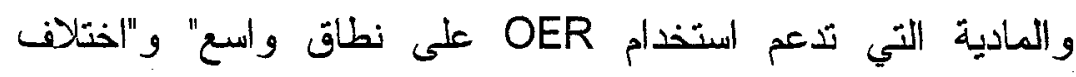

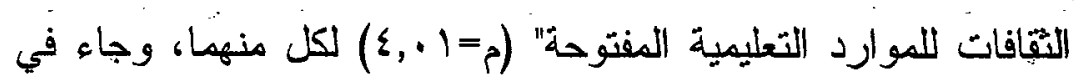
المرتبة الخامسة "صعوبة الوصول إلى الموارد المفتوحة بالنسبة

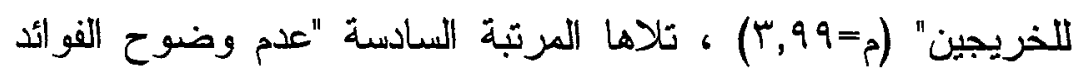

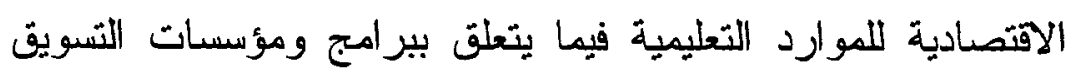

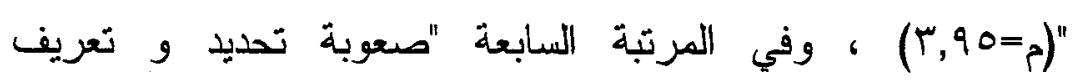

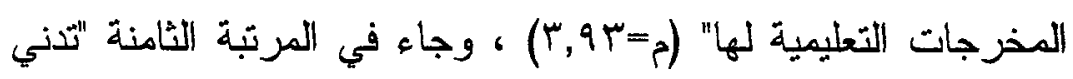

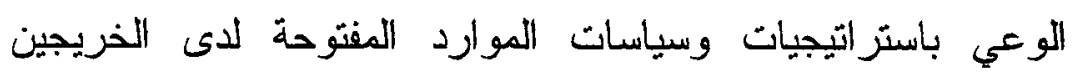

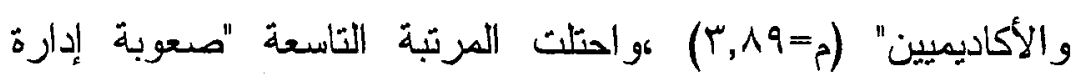

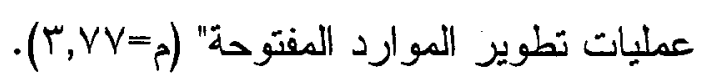

وكان أقل درجة موافقة من وجهة نظر أفراد العينة للفقرة

"صعوبة التطويز و المحافظة على البرامج العنكبوتية لاستضافة الموارد 

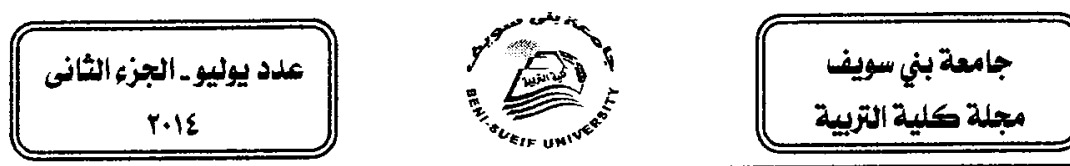

التعليمية على الانترنت للمشاركة في المحتوى" حازت على متوسط حسابي (r,V ) ( إجابة السؤال الرابع: الرئ

ما الفرص المتاحة أمام الموارذ التعليمية المفتوحة لدعم التعلم المستمر لدى خريجي الجامعات السعودية؟

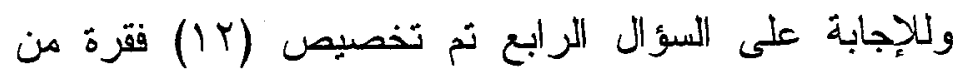

الاستبيان، ودلت النتائج أن قيمة المتوسط العام لمجموع استجابات أفراد عينة الدراسة لمحور الفرص المتاحة أمام الموارد التعليمية

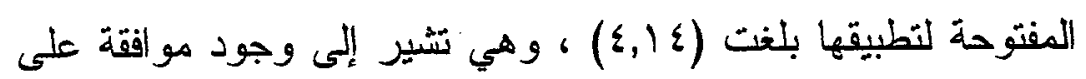
فقرات هذا المحور، وحصلت فقرات المحور على منوسطات حسابية تقع ما بين درجة أوافق و أوافق بشدة حيث تراوحت المتوسطات

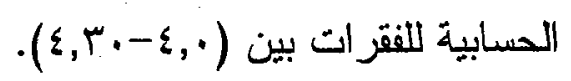

إذ احتلت المرتبة الأولى الفقرة "إيجاد الحاجة المستصرة للنعلم وتحسين جودته" حيث حصلت على أعلى متوسط في الموافقة لدى عينة البحث من مجتمع الدر اسة (م= • ؟, ع).

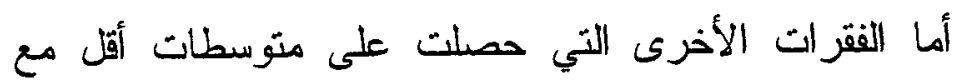

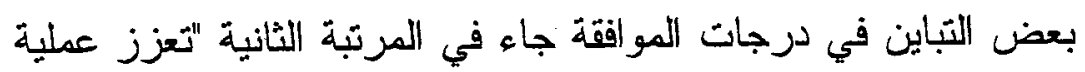

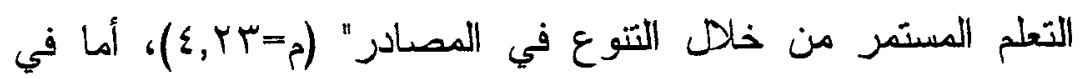
المرتبة الثالثة "تهدف إلى تحسين نوعية التعلم وخفض تكاليف التعليم"

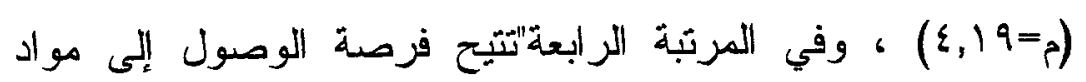

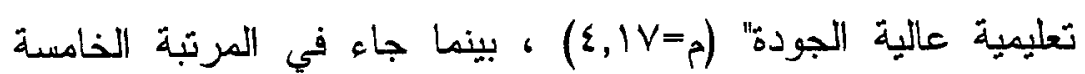
"تتمية وتوسيع الرو ابط بين الجامعات و نعزيز علاقات طويلة الأجل" (م) 
الاستر اتيجيات التعليمبة و التدريسية المناسبة لتحقيق النتائج التعليمية المحددة" و "تشجع التفكير الناقد لديك من خلا مشاركتاك في الأنشطة"

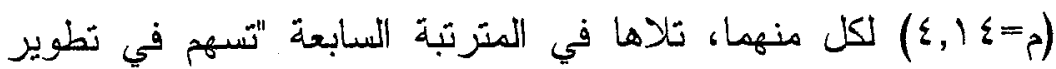

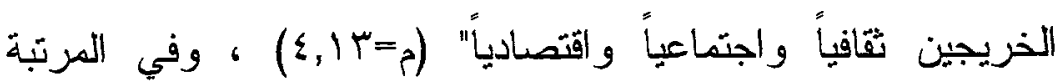
الثامنة "تضمن الاستدامة طويلة الأجل للمشاريع التعليمية المفتوحة" وائية (م=11, (2)، وجاء في المرتبة التاسعة "تثيح فرصدة التعاون المحلي

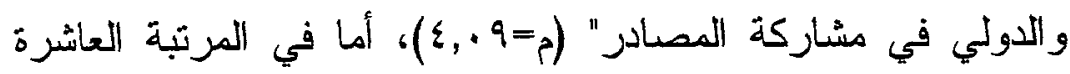
"توفز التدريب اللزمم الذي يلبي احتياجات سوق العمل" (م=ع .,ع). وكان أقل درجة موافقة من وجهة نظر أفراد العينة للفقزة

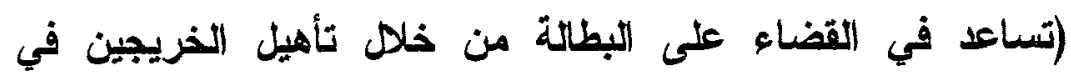

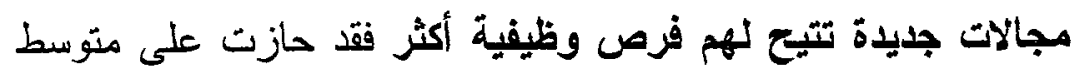

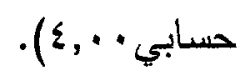
التوصيات والمقترحات التوصيات: على ضوء النتائج السابقة يمكن تقديم التوصيات الآثية: 1- نشر ثقافة الانفتاح ورفع الوعي بأهمية استخدام الموارد التعليمية المفتوحة كمصدر تعليمي لاى الخريجين. Y- ضرورة اهنمام جامعات المملكة العربية السعودية بالموارد التعليمية المفتوحة لارتباطه الوثيث باحتياجات المجنمع محلياً و إقليماً ودولياً. r- تقديم الدعم المادي والمعنوي للطاقم الأكاديمي للمساهمة في تطوير وتحسين المحتوى التعليمي الرثمي الذي يسهم في ضمان جودة التعليم للخريج. 


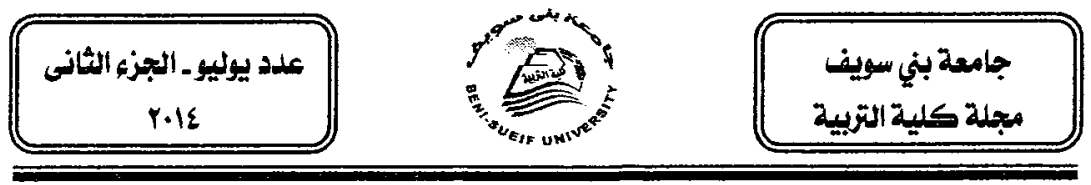

ع- تطوير السياسات المحلية لانتقاء استراتيجيات تعليمية جديدة -

المو ارد التعليمية المفتوحة - للسعي في توفير تعليم ذو نكلفة قليلة و استدامة طويل المدى .

- إنشاء منصات للموارد التعليمية المفتوحة لخلق بيئات اليكترونية

إجزائية ومستقرة يمكن اكتشافها و الاستفادة منها. المقترحات:

بناء على نتائج هذه الدراسة تقترح الباحثة إجراء الدراسات الآتية:

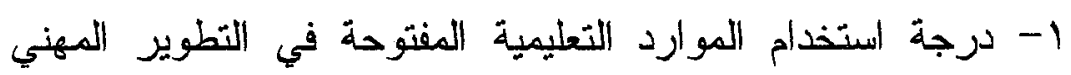
لأعضاء هيئة التدريس في جامعات المملكة العربية السعودية. ץ- دراسة العلاقة بين دور الموارد التعليمية المفتوحة والتمية الاقتصادية"رؤية مستقبلية".

r- إجراء درابة مقارنة بين مدى إمكانية تطبيق الموارد الثعليمية

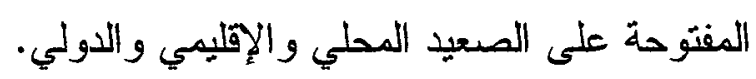

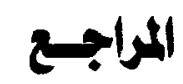

$$
\text { أولاً:المراجع العربية }
$$

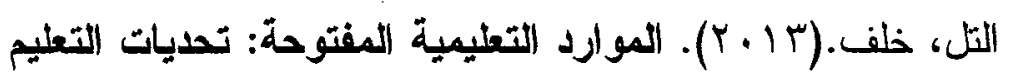
والتعلم في الدول العربية. ورقة عمل مقدمة في المؤتمر الدولي الثاني للجمعية العمانية لثقتيات التعليم. عمان. الحسيني، عزة احمد(ب ( • (ب). اقتصاد المعرفة و التعلم مدى الحياة: دراسة إقليمية لخبرة الاتحاد الأوروبي وإمكانية الإفادة منها في

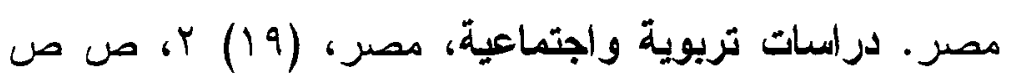
$.19 \lambda-1.1$ 


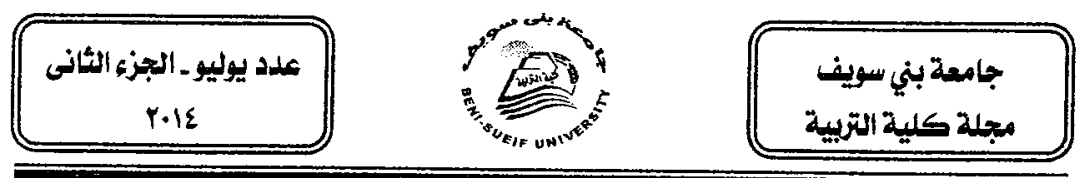

الخطة المستقبلية للتعليم الجامعي في المملكة العربية السعودية

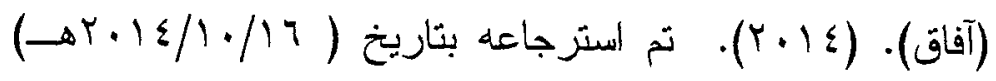

طلى الر ابط: http://aafaq.mohe.gov.sa/default.aspxhg

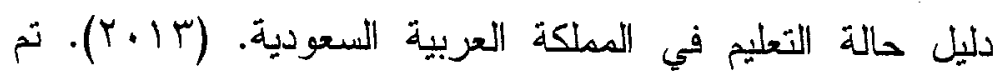

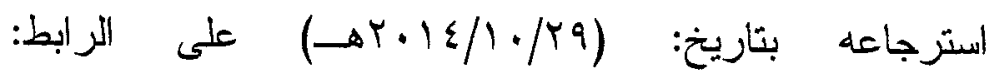
.http://goo.gl/tnhOiI

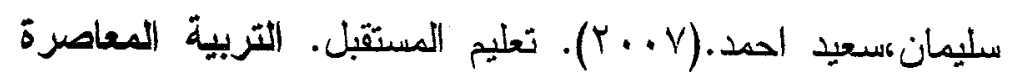

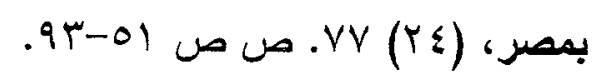
• عيد، هالة فوزي. (Y (Y). دور التعلم المستمر في تطوير التتمية البشرية كأحد متطلبات بناء اقتصاد المعرفة في الدول

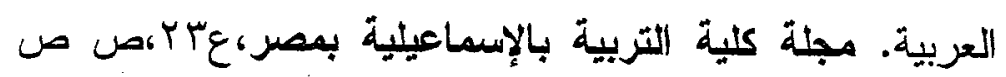
$1 \leq \Lambda .-1 \cdot V$

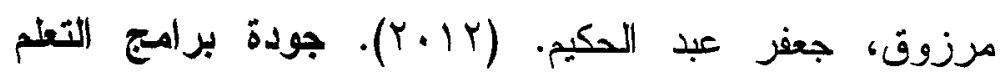
المستمر: "تصور مقترح للتطور" ـ ورقة عمل عمل مقدمة في المؤتمر الدولي العلمي التاسع: التعليم من بعد والتعليم المستمر أصالة

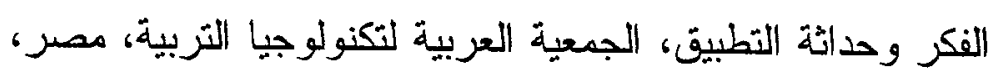

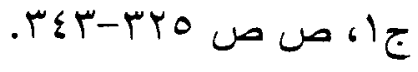

$$
\begin{aligned}
& \text { ثانياً:المراجع الأجنبية }
\end{aligned}
$$

-Atkins, D. E., Brown, J. S., Hammond, A. I. (2007). A Review of the Open Educational Resources (OER) Movement Achievements, Challenges, and New Opportunities. [Available online]. Retrieved Aug 8, 2014, From: 

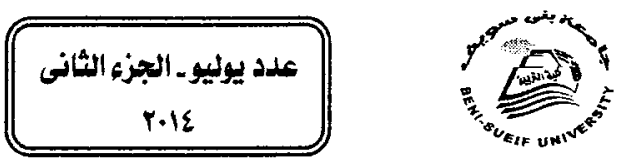

جامعة بني سويف

مجلة كلية التببية

http://www.hewlett.org/uploads/files/

ReviewoftheoERMovement.pdf

- Breck, J. (2007). Introduction to Special Issue on Opening Educational Resources. Educational Technology. $47(6)$. 3-5.

- Muller, N.J., Harrison, J.E., Raju, J. , \& Moodley, S. (2011). Discussion Paper on Open Access. Discussion paper, Durban University of Technology, .. [Available online].Retrieved Aug 12,2014 , from:

http://www.cluteinstitute.com/ojs/i ndex.php/IBER/article/viewFile/7986 18040

- UNESCO. (2002). Forum on the impact of open courseware for higher education indeveloping countries: Final report. [Available online]. Retrieved Aug 12, 2014, from

http://wcet.info/resources/publicat ions/unescofinalreport.pdf.

- Browne, T. ,Holding, R. . Howell, A\&Dyer, S.R (2010). The challenges of OER to Academic Practice. Journal of Interactive Media in Education. Retrieved Aug, 14, 2014, from:

http://files.eric.ed.gov/fulltext/E J910518.pdf

- Yuan,L.,Mac Neills., \& KraanW. (2008.) Open Educational Resources Opportunities and Challenges for Higher Education.Joint Information Systems 

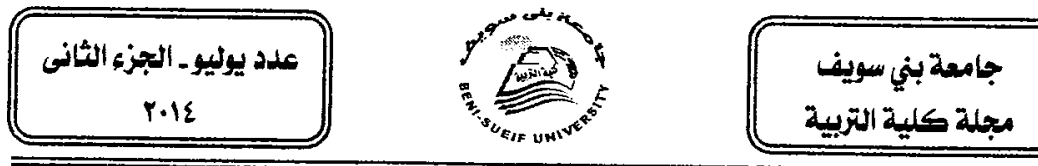

Committee

(JISC)

CETIS.

[Available online]. Retrieved Aug 20, 2014, from: http://wiki.cetis.ac.uk/images/0/Ob/OE R Briefing Paper.pdf

- OECD (2007). Giving Knowledge for Free: the Emergence of Open Educational Resources, [Available online]. Retrieved Aug 10, 2014, from: http://tinyurl.com/62hjx6

- HE UNIVERSITY OF THE WEST INDIES OPEN CAMPUS, (2010). Cape Town Open Education Declaration: Unlocking the promise of open educational [Available online] Retrieved Aug 10, 2014, from http://www.open.uwi.edu/sites/default/ files/P11Capetown.pdf

- Falconer, I., Littlejohn, A., McGill, L., and Beetham, H., (2014)" Motives and tensions in the release of Open Educational Resources: the JISC UKOER. [Available online]. Retrieved Aug 8, 2014, http://bit. Iy/motivespaper

- Almarwani, M (2013). OER in Saudi Arabia. [Available online]. Retrieved Aug 10, 2014, from: http://poerup.referata.com/w/images/OE $R$ in Saudi Arabia.pdf

- Hussain , M.S., Alhassan, A.U., \& Kamba , I.N. (2013). Continuing Education in Nigeria (meaning objectives, forms and prospects), European Scientific Journal, Retrieved Aug 10, 2014, from: 

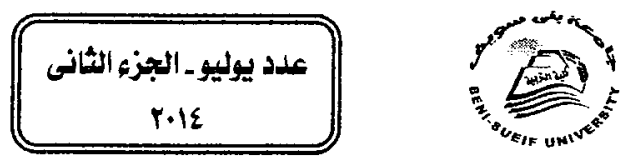

http://eujournal.org/index.php/esj/art icle/view/956/986

- Hall ,B.(2009). Higher Education, Community Engagement, and the Public Good :Building the Future of Continuing Education in Canada, Canadian Journal of University Continuing Education, (35) 1. pp 11-23

- Kozinska , K.; Kursun, E.; Wilson, T.; MC Andrew, P.; Scanlon, E. and Jones, A. (2010). Are open educational resources the future of e-learning?. 3rd International Future-Learning Conference: Innovations in Learning for the Future, Istanbul, Turkey, . [Available online]. Retrieved Aug 8, 2014, from http://kn.open.ac.uk/public/document.c fm?docid=13101

- Sclater, N. (2010).Open Educational Resources: Motivations, Logistics and Sustainability, Content Management for E-Learning, Springer. . [Available online].Retrieved Aug 13,2014 From www.springerlink. com.

\section{about}

UNESCO, (2013). Why should I care online].Retrieved Aug 10,2014 From: http://goo.gl/IMgoRo

- Yang, J \& Cotera , R(2011).Conceptual Evolution and Policy Developments in Lifelong Learning, UNESCO Institute for Lifelong Learning (UIL) (Germany), [Available online]. Retrieved Aug 13,2014 


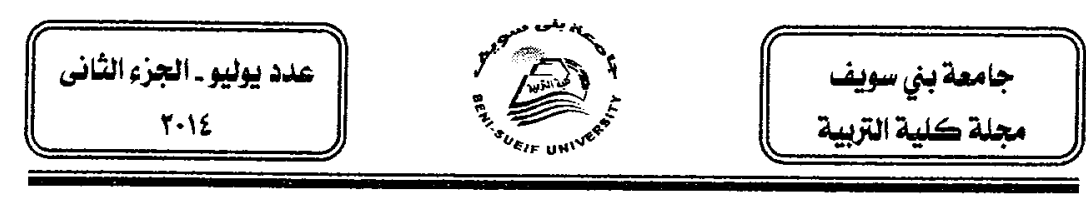

http://unesdoc.unesco.org/images/0019/ 001920/192081e.pdf

- Shanghai Education Commission , (2010). The Development of Lifelong Learning and Learning Society in Shanghai. [Available online].Retrieved Aug 13,2014 Fromhttp://www.moe.edu.cn/edoas/websit e18/36/info1209359935130136.ht

- Williams , H.(2010). Benefits and Challenges of OER for Higher Education Institutions, Centre for Educational Technology, University of Cape Town. [Available online] . Retrieved Aug 13,2014 From:

http://wWw.col.org/SiteCollectionDocume nts/OER BenefitsChallenges presentation .pdf

- UNESCO, ( 2004). global education digest 2004 Comparing Education Statistics Across the World. [Available online].Retrieved Aug 10,2014 From http://www.unesco.org/education/docs/E $\mathrm{N}$ GD2004 v2.pdf 